\title{
A Macintosh software package for simulation of human red blood cell metabolism
}

\author{
I-Der Lee and Bernhard O. Palsson \\ Cellular Biotechnology Laboratory, Department of Chemical Engineering, University of Michigan, Ann Arbor, MI, USA
}

\begin{abstract}
We have developed a computer software package for Macintosh to simulate the metabolism and hemoglobin binding affinity of human red blood cell. The model is capable of simulating hemoglobin binding of ligands, metabolite concentrations, and metabolic fluxes at physiological steady state and in response to extracellular parameter variations, such as $\mathrm{pH}$, osmolarity, glucose, and adenine concentrations. The kinetic parameters of enzymes, extracellular conditions, and initial intracellular metabolite concentrations can be specified by the user in order to model a particular situation. The software is use friendly, utilizing menu, window, and mouse to interact with the user. It also provides a pathway map of the red cell, which allows a direct access to enzyme kinetics by clicking the enzymes in the map.
\end{abstract}

Metabolic model; Human erythrocyte; Erythrocyte metabolism

\section{Introduction}

Red blood cells have been subjected to intensive studies due to their vital functions in human body. The basic physiological function of the red cell is to deliver oxygen and carbon dioxide between the lungs and tissues. The metabolism of the red cell is thus designed to regulate the hemoglobin binding affinity with the two gases and maintain the viability of the cell. The most important metabolites involved in the red cell functions are 23DPG and ATP, concentrations of which can be sufficiently supplied and regulated by glycolysis, pentose pathway, and nucleotide synthesis processes that constitute the red cell metabolism.

Correspondence: Bernhard O. Palsson, Cellular Biotechnology Laboratory, Department of Chemical Engineering, University of Michigan, Ann Arbor, MI 48109-2136, USA.
A large body of experimental data have been accumulated for the last three decades, providing detailed information about individual enzymes in the red cell. Efforts in collecting these information and organizing them into quantitative models for red cell metabolic pathways began in the early 1970s [1]. Several metabolic models for the red cell have since been developed, which mainly consider glycolysis and pentose pathway [1-9]. However, there was a lack of a comprehensive metabolic model which can be used to analyze the red cell metabolism as a whole living cell.

We thus set out to construct a full model for the red cell, which account for glycolysis, pentose pathway, nucleotide synthesis, cation transports, magnesium complexation, $\mathrm{pH}$ dependence of enzymes, hemoglobin binding, electroneutrality, and osmotic balance [10-12]. This model considers all major metabolic reactions, interaction between intracellular metabolism with extracellular perturbation, regulation of hemoglobin binding by its 
ligands, and $\mathrm{pH}$ dependence of enzyme kinetics. We have verified the model calculation against literature experimental data; the model can predict the physiological steady state of red cell metabolism [11] and dynamic response of the red cell to an extracellular $\mathrm{pH}$ perturbation [12].

A software package that simulates the red cell metabolic model has been writen for Apple Macintosh, utilizing the friendly operating system of the computer to interact with users. The package allows the user to change kinetic parameters for enzymes, to calculate steady state metabolite concentrations and fluxes, dynamic response of the cell to extracellular perturbations, variation of each enzyme activity as functions of extra- and intracellular conditions, and hemoglobin binding curves of ligands.

This paper will describe the basic features of the mathematical model, the structure of the program, and the capability of the simulator, and finally provide several sample calculations.

\section{Computational methods and theory}

The red cell metabolic model accounts for 33 metabolites, 41 enzymatic reactions, 2 physicochemical constraints, and several chemical equilibrium reactions, which are individually calculated in separated subroutines. The model contains 33 ordinary differential equations with 33 metabolites concentrations as dependent variables. The kinetic rate laws and equations used to describe metabolic reactions, cofactor balances, membrane transport, osmotic balance, electroneutrality, $\mathrm{Mg}$ complex balance, and hemoglobin binding in the red cell are described as follows.

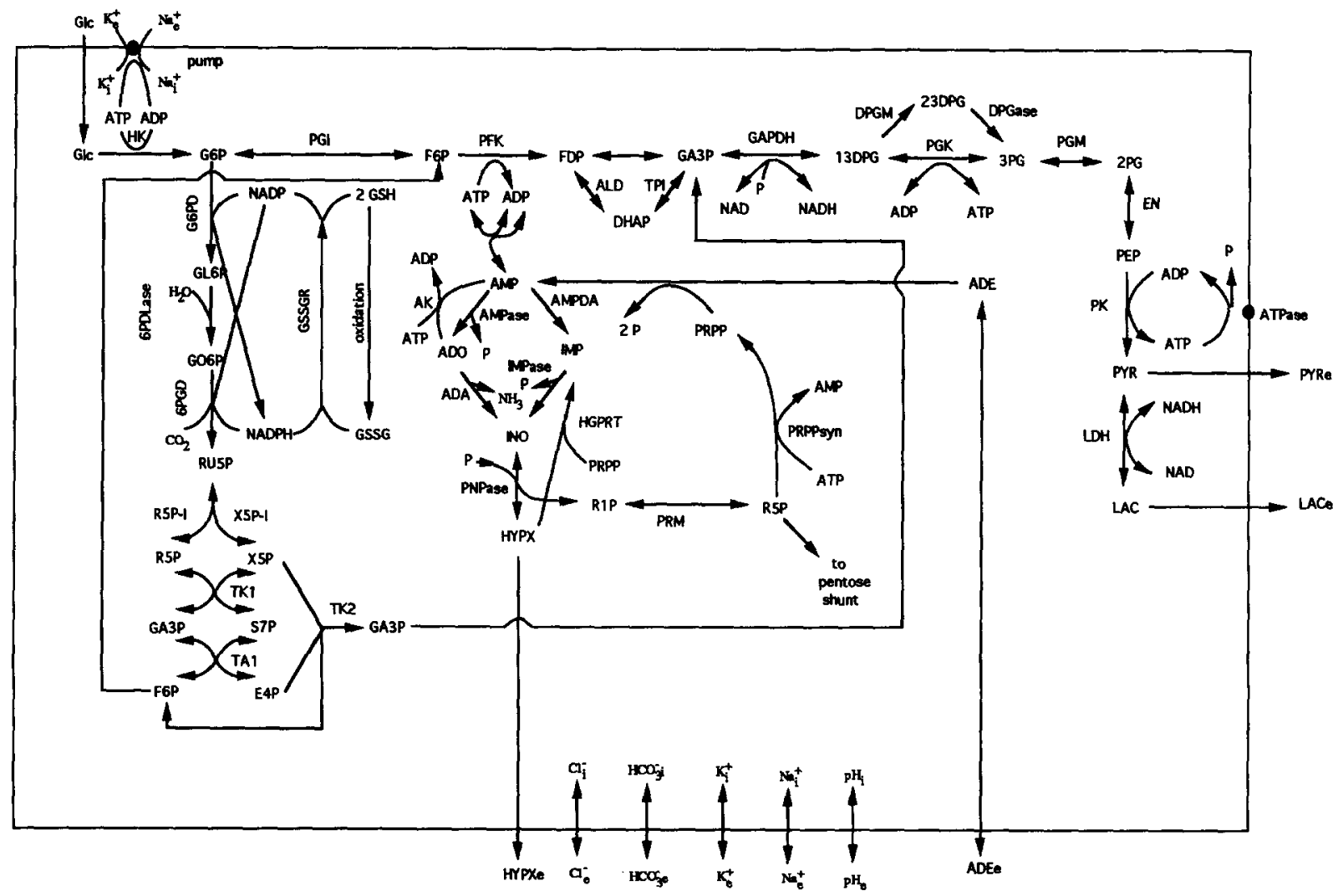

Fig. 1. The mathematical model of human red cell metabolism. 


\subsection{Metabolic reactions}

The equations that describe the transient changes in metabolite concentrations are simply dynamic mass balances. The change in amount of a substance per cell per unit time is given by the sum of all the synthetic rates minus the sum of all degradation rates (see Fig. 1):

$$
\frac{d V C_{i}}{d t}=V \sum_{j=1}^{n} \nu_{i j} v_{f_{i j}}-V \sum_{k=1}^{n} \nu_{i k} v_{d_{i k}}
$$

where $C_{i}$ is the concentration of variable $i ; v_{f_{i j}}$ is

\section{TABLE 1}

Red cell intermediates and their abbreviations

\begin{tabular}{ll}
\hline Abbreviation & Metabolic intermediates \\
\hline G6P & Glucose 6-phosphate \\
F6P & Fructose 6-phosphate \\
FDP & Fructose 1,6-diphosphate \\
DHAP & Dihydroxyacetone phosphate \\
GA3P & Glyceraldehyde 3-phosphate \\
3PG & 3-phosphoglycerate \\
2PG & 2-phosphoglycerate \\
PEP & Phosphoenolpyruvate \\
PYR & Pyruvate \\
LAC & Lactate \\
1,3DPG & 1,3-Diphosphoglycerate \\
2,3DPG & 2,3-Diphosphoglycerate \\
NAD & Nicotinamide adenine dinucleotide \\
ATP & Adenosine tri-phosphate \\
ADP & Adenosine di-phosphate \\
AMP & Adenosine mono-phosphate \\
ADO & Adenosine \\
ADE & Adenine \\
GL6P & 6-Phosphoglucono- $\delta$-lactone \\
GO6P & 6-Phosphogluconate \\
NADP & Nicotinamide adenine phosphate \\
GSH & Glutathione \\
RU5P & Ribulose 5-phosphate \\
R5P & Ribose 5-phosphate \\
X5P & Xylulose 5-phosphate \\
S7P & Sedoheptulose 5-phosphate \\
E4P & Erythrose 4-phosphate \\
PRPP & 5-phosphoribosyl-1-pyrophosphate \\
IMP & Inosine mono-phosphate \\
INO & Inosine \\
HX & Hypoxanthine \\
R1P & Ribose 1-phosphate \\
K & Sotassium \\
Na & \\
\hline & \\
\hline &
\end{tabular}

the $j$ th synthetic rate of concentration variable $i$, and $v_{d_{i k}}$ is the $k$ th degradation rate of concentration variable $i$ (the $v$ 's represent volumetric reaction rates). The volume of the cell is represented by $V$ and time by $t$. The stochiometric coeffi-

\section{TABLE 2}

Red cell metabolic enzymes and their abbreviations

\begin{tabular}{ll}
\hline Abbreviation & Enzymes \\
\hline HK & Hexokinase \\
PGI & Phosphoglucoisomerase \\
PFK & Phosphofructokinase \\
ALD & Aldolase \\
TPI & Triose phosphate isomerase \\
GAPDH & Glyceraldehyde phosphate dehydrogenase \\
PGK & Phosphoglycerate kinase \\
DPGM & Diphosphoglycerate mutase \\
DPGase & Diphosphoglycerate phosphatase \\
PGM & Phosphoglyceromutase \\
EN & Enolase \\
PK & Pyruvate kinase \\
LDH & Lactate dehydrogenase \\
PYRex & Pyruvate export \\
LACex & Lactate export \\
AMPase & Adenosine monophosphate phosphohydrolase \\
ADA & Adenosine deaminase \\
AK & Adenosine kinase \\
ApK & Adenylate kinase \\
AMPDA & Adenosine monophosphate deaminase \\
ATPase & Adenosine triphosphate phosphohydrolase \\
AdPRT & Adenine phosphoribosyl transferase \\
G6PDH & Glucose-6-phosphate dehydrogenase \\
6PGL & 6-Phosphogluconolactonase \\
6PGLDH & 6-Phosphogluconate dehydrogenase \\
GSSGR & Glutathione reductase \\
GSH & Glutathione oxidase \\
R5P-I & Ribose-5-phosphate isomerase \\
Xu5P-I & Xylulose-5-phosphate epimerase \\
TKI & Transketolase \\
TKII & Transketolase \\
TA & Transaldolase \\
IMPase & Inosine monophosphatase \\
PNPase & Purine nucleoside phosphorylase \\
PRM & Phosphoribomutase \\
PRPPsyn & Phosphoribosyl pyrophosphate synthetase \\
HGPRT & Hypoxanthine-guanine phosphoryl transferase \\
'HXex & Hypoxanthine export \\
LeakK & Leak of potassium out of the red cell \\
Pump & Leak of sodium out of the red cell \\
\hline & Sodium/potassium pump \\
\hline
\end{tabular}




\section{TABLE 3}

The rate expressions used to describe the irreversible reactions in red cell glycolysis

The unit for a concentration is $\mathrm{mM}$, and the unit for a reaction rate is $\mathrm{mM} / \mathrm{h}$. The references shown are for the $\mathrm{pH}$ dependence of kinetic constants. For the kinetic expressions, see [11].

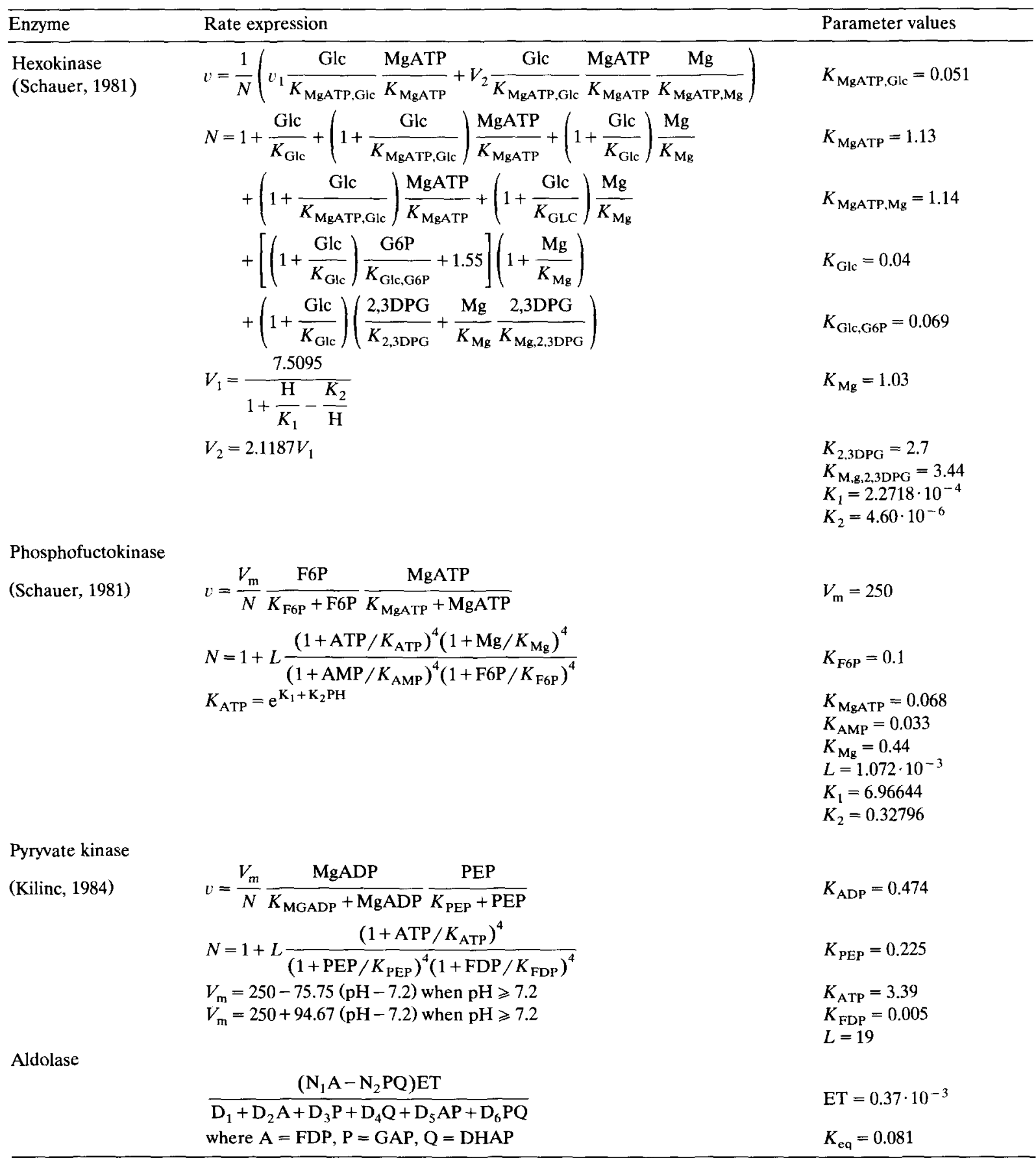


TABLE 3 (continued)

\begin{tabular}{ll}
\hline Aldolase & $K_{1}=3.85 \cdot 10^{7}$ \\
$N_{2}=\frac{\mathrm{N}_{1}}{K_{\mathrm{eq}}}$ & $K_{2}=8.388 \cdot 10^{5}$ \\
$D_{1}=K_{5}\left(K_{3}+K_{2}\right)$ & $K_{3}=6.84 \cdot 10^{6}$ \\
$D_{2}=K_{1}\left(K_{3}+K_{5}\right)$ & $K_{4}=4.032 \cdot 10^{7}$ \\
$D_{3}=K_{2} K_{4}$ & $K_{5}=2.52 \cdot 10^{5}$ \\
$D_{4}=K_{6}\left(K_{3}+K_{2}\right)$ & $K_{6}=23.076 \cdot 10^{6}$ \\
$D_{5}=K_{1} K_{4}$ & \\
$D_{6}=K_{4} K_{6}$ & \\
\hline
\end{tabular}

cients for the synthesis and degradation rates are given by $\nu_{i j}$ and $\nu_{i k}$, respectively.

The number of concentration variables in the red cell mode, $n$, is 33 (Table 1 ) and the number of reaction rates, $m$, is 41 (Table 2). The kinetic rate expression for the 41 enzymatic reactions in glycolysis, 23DPG bypass, equilibrium reactions, pentose pathway, glutathione metabolism, nucleotide synthesis, and membrane transport are given in Tables 3-10. These information about

\section{TABLE 4}

The equilibrium constants for the reversible reactions considered in this model [11]

The unit for a concentration is $\mathrm{mM}$.

\begin{tabular}{lll}
\hline Enzyme & Equilibrium expression & Constant \\
\hline PGI & $K_{\mathrm{PGI}}=\frac{\mathrm{F} 6 \mathrm{P}}{\mathrm{G} 6 \mathrm{P}}$ & $K_{\mathrm{PGI}}=0.41$ \\
TPI & $K_{\mathrm{TPI}}=\frac{\mathrm{DHAP}}{\mathrm{GAP}}$ & $K_{\mathrm{TPI}}=22.0$ \\
GAPDH & $K_{\mathrm{GAPDH}}=\frac{1,3 \mathrm{PPG} \text { NADH H }}{\mathrm{P} \text { GAP NAD }}$ & $K_{\mathrm{GAPDH}}=1.1294 \cdot 10^{-6}$ \\
PGK & $K_{\mathrm{PGK}}=\frac{3 \text { PG ATP }}{\mathrm{ADP} 1,3 \mathrm{DPG}}$ & $K_{1}=25$ \\
PGM & $K_{\mathrm{pgk}}=K_{1}+K_{1} \mathrm{Mg}^{0.46}$ & $K_{2}=3575$ \\
EN & $K_{\mathrm{PGM}}=\frac{3 \mathrm{PG}}{2 \mathrm{PG}}$ & $K_{\mathrm{PGM}}=6.8$ \\
LDH & $K_{\mathrm{EN}}=\frac{\mathrm{PEP}}{2 \mathrm{PG}}$ & $K_{\mathrm{EN}}=0.59$ \\
AdK & $K_{\mathrm{LDH}}=\frac{\mathrm{LAC} \mathrm{NAD}}{\mathrm{PYR} \mathrm{NADH} \mathrm{H}}$ & $K_{\mathrm{LDH}}=7.075 \cdot 10^{5}$ \\
& $K_{\mathrm{AdK}}=\frac{\mathrm{ATP} \mathrm{AMP}}{\mathrm{ADP}}$ & $K_{1}=0.081$ \\
& $K_{\mathrm{AdK}}=\frac{0.23\left(\mathrm{Mg}+K_{1}\right)\left(\mathrm{Mg}+K_{2}\right)}{\left(\mathrm{Mg}+K_{2}\right)^{2}}$ & $K_{2}=0.81$ \\
PRM & $K_{\mathrm{PRM}}=\frac{\mathrm{R} 5 \mathrm{P}}{\mathrm{R} 1 \mathrm{P}}$ & $K_{3}=22.2$ \\
PNPase & $K_{\mathrm{PNPase}}=\frac{\mathrm{HX} \mathrm{R1P}}{\mathrm{P} \mathrm{INO}}$ & $K_{\mathrm{PRM}}=13.30$ \\
\hline
\end{tabular}


enzyme kinetics are described in detail in the individual papers cited and summarized in [1012].

The kinetics of metabolic pathways are coupled to several constraints: cofactor conservation, osmotic balance, electroneutrality, hemoglobin binding, magnesium complexation, and $\mathrm{pH}$ sensitivity of metabolic enzymes. Thus, the complete kinetic description consists of a combination of set of differential-algebraic equations, which have to be solved simultaneously to represent the metabolic state of the cell.

\subsection{Cofactor balances}

The model assumes that the total amount of the cofactors of redox metabolism are conserved. The conservation equations for these cofactors can be written as:

$N_{T}=N A D^{+}+N A D H$

$N P_{T}+N A D P^{+}+N A D P H$

$G_{T}=2 G S S G+G S H$

In these expressions, NADH and NADPH correspond to one stoichiometric redox of hydrogen equivalent of the system whereas GSH corresponds to $1 / 2$ hydrogen equivalent only.

\subsection{Membrane transport}

Membrane transport of glucose, adenine, water, sodium, potassium, pyruvate, lactate, hydrogen, chloride, and bicarbonate ions is considered in the red cell model (Fig. 2). Water has the highest transport rate, glucose and adenine transport is slower, chloride, bicarbonate, and hydrogen ions are even slower, and the time constants for the transport of sodium, potassium, pyruvate, and lactate ions are longer than those for other compounds. Only the transport of sodium, potassium, pyruvate, and lactate, is expressed in terms of rate equations (Table 10); all other transport is assumed to be at thermodynamic equilibrium across the cell membrane.

The function of chloride, bicarbonate, and hydrogen ions transport is to neutralize electrical charges inside and outside the cell, whereas water transport balances the osmotic pressure across the membrane. Glucose and adenine are taken up by the cell at such a fast rate that their intraand extracellular concentrations are assumed to be the same. Sodium and potassium ions traverse the cell membrane via a sodium/potassium pump, and passive and facilitated fluxes. The pump utilizes metabolic energy, in term of ATP, to transport sodium and potassium ions against their concentration gradients across the membrane. On the other hand, the driving force for

\section{TABLE 5}

The rate expressions used to describe the kinetics of the reactions in the 2,3DPG bypass

The unit for a concentration is $\mathrm{mM}$, and the unit for a reaction rate is $\mathrm{mM} / \mathrm{h}$. The references shown are for the $\mathrm{pH}$ dependence of kinetic constants. For the kinetic expressions, see [11].

\begin{tabular}{lll}
\hline Enzyme & Rate expression & Parameter values \\
\hline $\begin{array}{ll}\text { DPG mutase } \\
\text { (Werner, 1985) }\end{array}$ & \multicolumn{1}{c}{$1,3 \mathrm{DPG}$} & \\
& $v=K_{\mathrm{DPGM}} \frac{K_{2,3 \mathrm{DPG}}=0.04}{1+2,3 \mathrm{DPG} / K_{2,3 \mathrm{DPG}}}$ & $K_{0}=2.75 \cdot 10^{5}$ \\
& $K_{\mathrm{DPGM}}=k_{0} \mathrm{e}^{-K_{1}+K_{2} \mathrm{PH}, \text { if } \mathrm{pH}>6.85}$ & $K_{2}=2.828$ \\
& $K_{\mathrm{DPGM}}=0$, if pH $<6.85$ & \\
& & $V_{\mathrm{m}}=0.52$ \\
2,3DPG phosphatase & $v=\frac{V_{\mathrm{m}} 2,3 \mathrm{DPG}}{K_{2,3 \mathrm{DPG}}+2,3 \mathrm{DPG}}$ & $K_{1}=8.0287$ \\
& $K_{2,3 \mathrm{DPG}}=0.5028 \mathrm{e}^{-K_{1}+K_{2} \mathrm{PH}}$ & $K_{2}=0.98217$ \\
\hline
\end{tabular}


TABLE 6

The rate expressions used to describe the kinetics of the oxidative reactions in the pentose pathway

The unit for a concentration is $\mathrm{mM}$, and the unit for a reaction rate is $\mathrm{mM} / \mathrm{h}$. The references shown are for the $\mathrm{pH}$ dependence of kinetic constants. Kinetic expressions are given in [11].

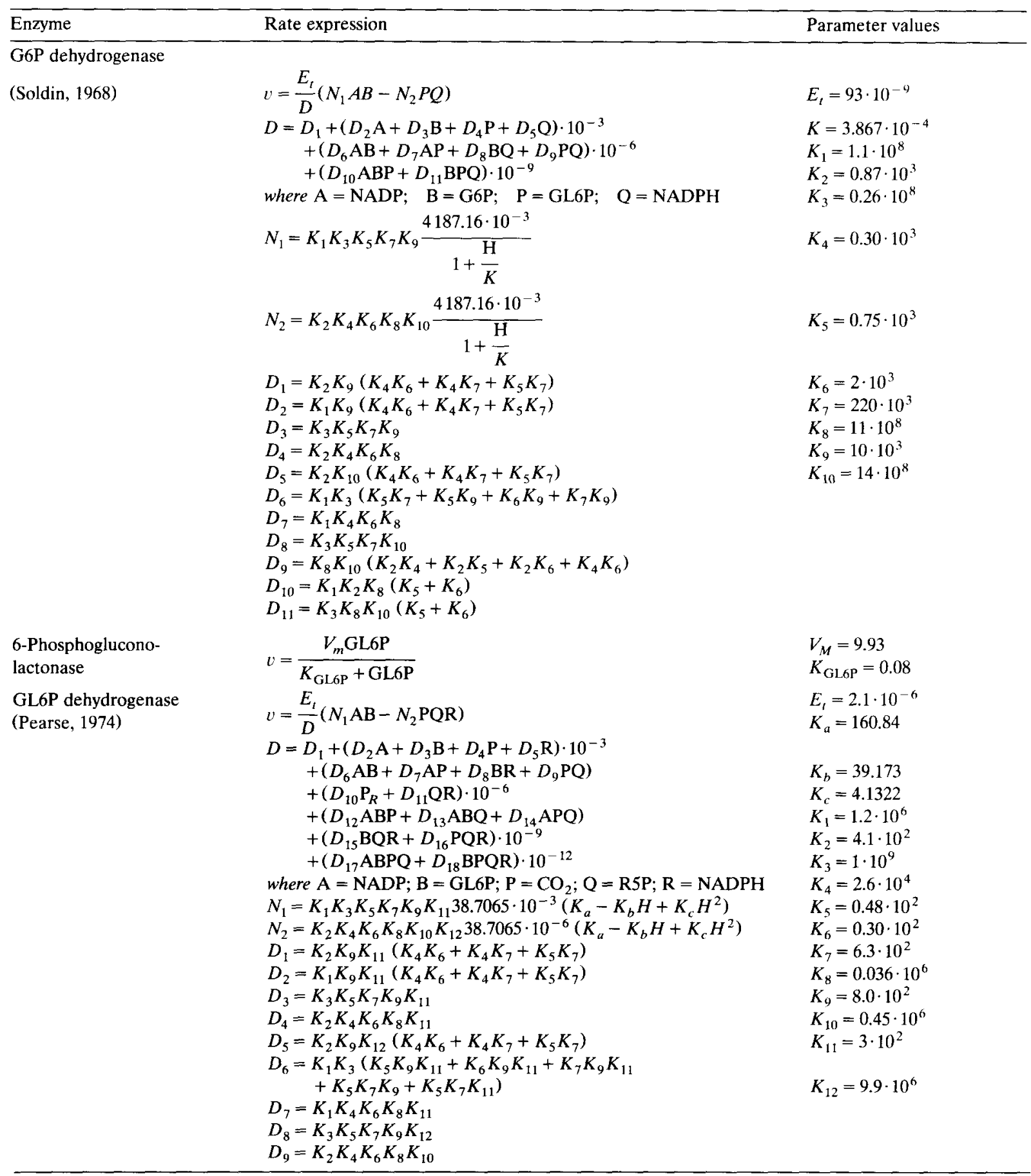


TABLE 6 (continued)

\begin{tabular}{|c|c|c|}
\hline Enzyme & Rate expression & Parameter values \\
\hline & $\begin{array}{l}D_{10}=K_{2} K_{4} K_{6} K_{8} K_{12} \\
D_{11}=K_{2} K_{10} K_{12}\left(K_{4} K_{6}+K_{4} K_{7}+K_{5} K_{7}\right) \\
D_{12}=K_{1} K_{3} K_{8} K_{11}\left(K_{5}+K_{6}\right) \\
D_{13}=K_{1} K_{3} K_{5} K_{7} K_{10} \\
D_{14}=K_{1} K_{4} K_{6} K_{8} K_{10} \\
D_{15}=K_{3} K_{5} K_{7} K_{10} K_{12} \\
D_{16}=K_{8} K_{10} K_{12}\left(K_{2} K_{4}+K_{2} K_{5}+K_{2} K_{6}+K_{4} K_{6}\right) \\
D_{17}=K_{1} K_{3} K_{8} K_{10}\left(K_{5}+K_{6}\right) \\
D_{18}=K_{3} K_{8} K_{10} K_{12}\left(K_{5}+K_{6}\right)\end{array}$ & \\
\hline
\end{tabular}

the passive and facilitated fluxes is the concentration gradient. The steady state concentrations of both ions are the result of a balance between the pump, and the passive and facilitated fluxes.

\subsection{Osmotic balance}

Osmotic pressure is balanced across the membrane according to the following equations [10]:

$\Pi_{i}=\Pi_{e}$

and

$\Pi_{i}=R T \sum_{j} \phi_{i j} C_{i j}$

$\Pi_{e}=R T \sum_{j} \phi_{e j} C_{e j}$

where $R$ is the ideal gas constant, $T$ denotes the temperature, $\phi$ represents the osmotic coefficient, and $C_{j}$ is the concentration of component $j$. The osmotic pressure balance is satisfied by the fast water transport through the membrane. The result of the balance also determines the cell volume.

The intracellular osmolarity can be partitioned into 4 terms according to the membrane permeability of substrates and the volume-dependence of substrate concentrations:

$\Pi_{i}=\Pi_{1}+\Pi_{2}+\Pi_{3}+\Pi_{H b}$ where:

- $\Pi_{1}$ is contributed by slow membrane permeable metabolites and cations, such as G6P, FDP, ATP, and $\mathrm{Na}$, of which the rates of reaction are expressed in term of ordinary differential equations in the simulator. The concentrations of substrates included in $\Pi_{1}$ vary with the cell volume, since they have relatively small membrane permeability.

- $\Pi_{2}$ is contributed by relatively fast membrane permeable substrates, such as glucose and adenine, of which the intracellular concentrations can be assumed to be at equilibrium with the extracellular concentrations. Therefore, the magnitude of $\Pi_{2}$ is not a function of cell volume, when the external nutrient concentrations are constant.

- $\Pi_{3}$ is contributed by anions, such as $\mathrm{Cl}^{-}$and $\mathrm{CO}_{3}^{-}$, which transport instantaneously through the membrane to balance cation transport.

- $\Pi_{H b}$ is contributed by hemoglobin molecules. The changes in the osmotic coefficient of hemoglobin $\phi_{\mathrm{Hb}}$ as a function of its concentration is given by [13].

$\phi_{\mathrm{Hb}}=1.0+0.0645 \mathrm{Hb}+0.0258 \mathrm{Hb}^{2}$

where the concentration of hemoglobin varies with the red cell volume $v$ as $\mathrm{Hb}=\mathrm{Hb}^{0} / V$.

\subsection{Electroneutrality}

The law of electrical neutrality of solutions applies within and outside the erythrocyte. There 


\section{TABLE 7}

The rate expressions used to describe the kinetics of the non-oxidative reactions in the pentose pathway

The unit for a concentration is $\mathrm{mM}$, and the unit for a reaction rate is $\mathrm{mM} / \mathrm{h}$. The references shown are for the $\mathrm{pH}$ dependence of kinetic constants. Kinetic expressions are given in [19].

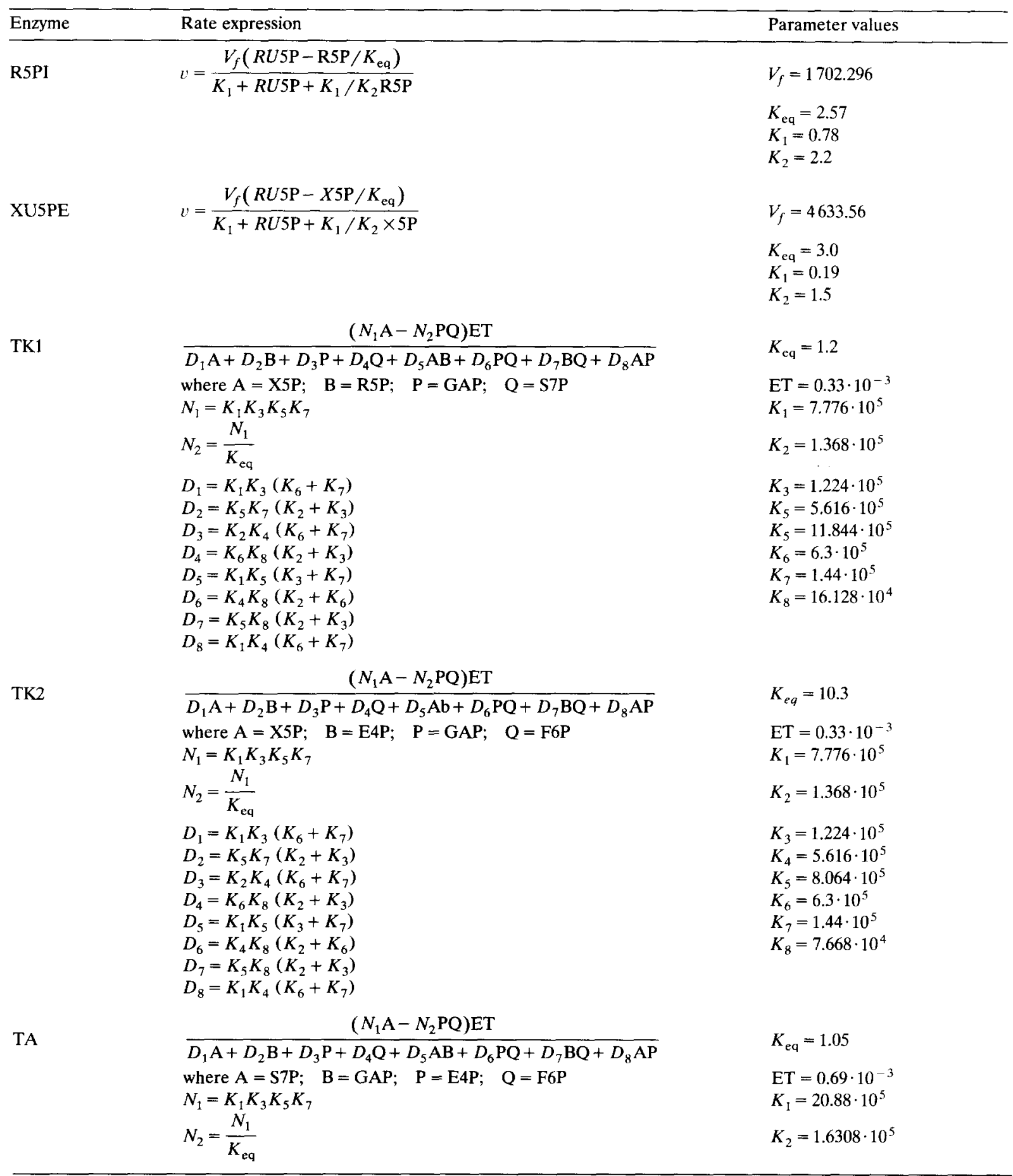


TABLE 7 (continued)

\begin{tabular}{lll}
\hline Enzyme & Rate expression & Parameter values \\
\hline TA & $D_{1}=K_{1} K_{3}\left(K_{6}+K_{7}\right)$ & $K_{3}=5.868 \cdot 10^{4}$ \\
& $D_{2}=K_{5} K_{7}\left(K_{2}+K_{3}\right)$ & $K_{4}=3.636 \cdot 10^{6}$ \\
& $D_{3}=K_{2} K_{4}\left(K_{6}+K_{7}\right)$ & $K_{5}=17.64 \cdot 10^{5}$ \\
& $D_{4}=K_{6} K_{8}\left(K_{2}+K_{3}\right)$ & $K_{6}=2.16 \cdot 10^{5}$ \\
& $D_{5}=K_{1} K_{5}\left(K_{3}+K_{7}\right)$ & $K_{7}=6.12 \cdot 10^{4}$ \\
& $D_{6}=K_{4} K_{8}\left(K_{2}+K_{6}\right)$ & $K_{8}=28.44 \cdot 10^{4}$ \\
& $D_{7}=K_{5} K_{8}\left(K_{2}+K_{3}\right)$ & \\
$D_{8}=K_{1} K_{4}\left(K_{6}+K_{7}\right)$ & \\
\hline
\end{tabular}

\section{TABLE 8}

The rate expressions used to describe the kinetics of the reactions of glutathione metabolism

The unit for a concentration is $\mathrm{mM}$, and the unit for a reaction rate is $\mathrm{mM} / \mathrm{h}$. The references shown are for the $\mathrm{pH}$ dependence of kinetic constants. Kinetic expressions are given in [11].

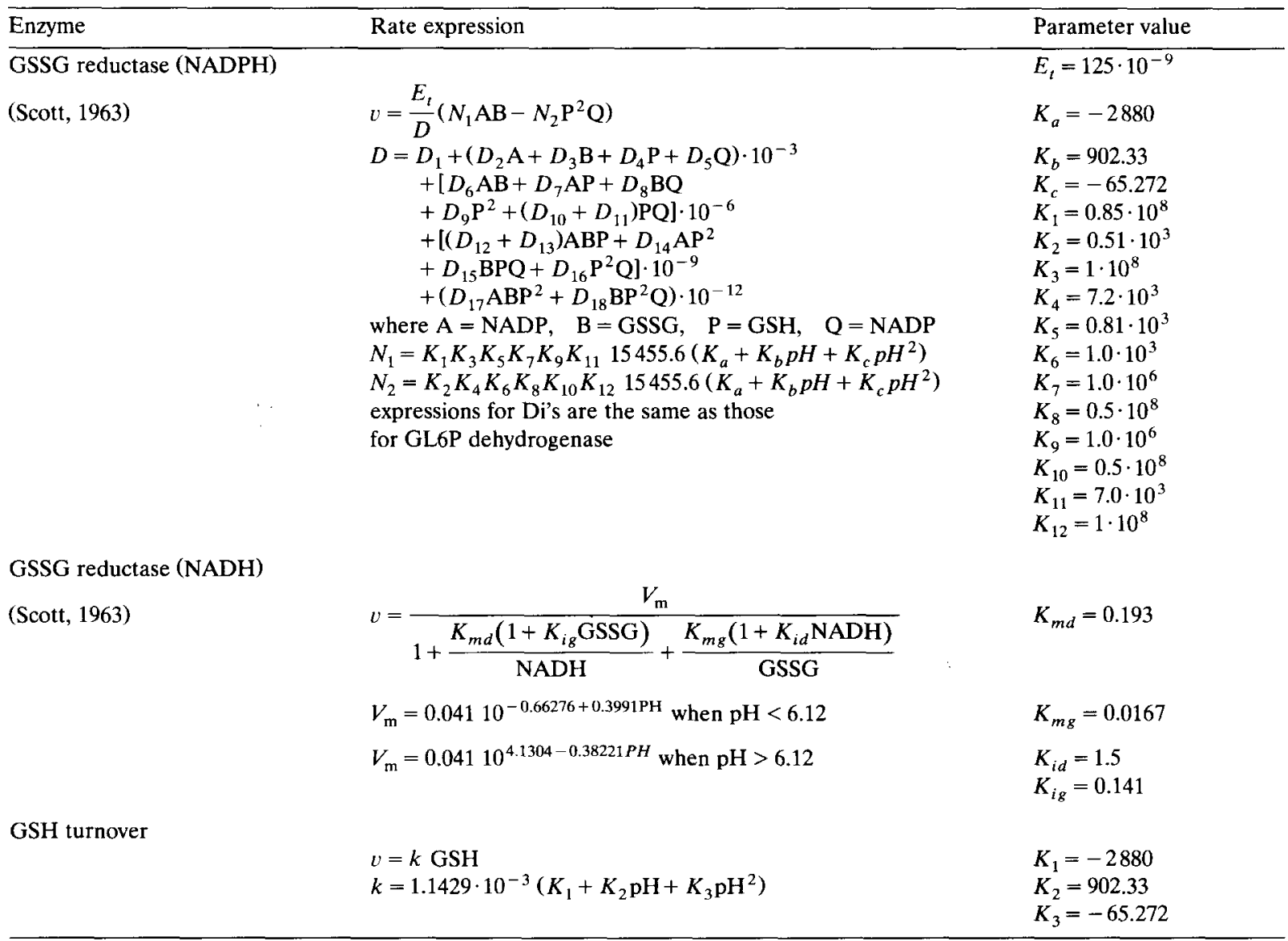




\section{TABLE 9}

The rate expressions used to describe the kinetics of the reactions involved in nucleotide synthesis

The unit for a concentration is $\mathrm{mM}$, and the unit for a reaction rate is $\mathrm{mM} / \mathrm{h}$. The references shown are for the $\mathrm{pH}$ dependence of kinetic constants. Kinetic expressions are given in [11].

\begin{tabular}{lll}
\hline Enzyme & Rate expression & Parameter values \\
\hline AMPase & $v=k$ AMP & $K_{1}=2.5642 \cdot 10^{-3}$ \\
(Heppel, 1951) & $k=\frac{1.6480}{1+\frac{\mathrm{H}}{K_{1}}+\frac{K_{2}}{\mathrm{H}}}$ & $K_{2}=1.2159 \cdot 10^{-6}$
\end{tabular}

Adenosine deaminase

(Daddona, 1977)

$$
\begin{aligned}
& u=\frac{V_{M} \mathrm{~A}}{K+\mathrm{A}} \\
& V_{m}=\frac{-36.348}{1+\frac{\overline{\mathrm{H}}}{K_{1}}+\frac{K_{2}}{\mathrm{H}}}
\end{aligned}
$$$$
K=0.052
$$$$
K_{1}=1.995 \cdot 10^{-4}
$$$$
K_{2}=3.162 \cdot 10^{-5}
$$

Adenosine kinase

(Meyskens, 1971)

$$
\begin{aligned}
& v=V_{m} \frac{\mathrm{ATP}}{K_{\mathrm{ATP}}+\mathrm{ATP}} \frac{\mathrm{A}}{K_{\mathrm{A}}+\mathrm{A}} \\
& V_{m}=\frac{8.6229}{1+\frac{\bar{K}_{1}}{\mathrm{H}}}
\end{aligned}
$$$$
K_{\text {ATP }}=0.8
$$$$
K_{A}=0.0004
$$$$
K_{1}=1.636 \cdot 10^{-4}
$$

AMP deaminase

$$
v=V_{m} \frac{\text { AMP }}{K+\mathrm{AMP}}
$$

$V_{\mathrm{M}}=0.01$

$K=0.8$

ATPase

(Dunham, 1961)

$$
\begin{aligned}
& v=K_{\text {ATPase }} \text { ATP } \\
& K_{\text {ATPase }}=\frac{0.415}{1+\frac{\mathrm{H}}{K_{1}}+\frac{K_{2}}{\mathrm{H}}}
\end{aligned}
$$

$K_{1}=3.7342 \cdot 10^{-3}$

$K_{2}=8.2714 \cdot 10^{-7}$

\section{AdPRT}

(Thomas, 1973)

$$
\begin{aligned}
& v=V_{m}=\frac{\mathrm{ADE}}{K_{\mathrm{ADE}}+\mathrm{ADE}} \frac{\mathrm{PRPP}}{K_{\mathrm{PRPP}}+\mathrm{PRPP}} \\
& V_{m}=\frac{0.202}{1+\frac{\mathrm{H}}{K_{1}}+\frac{K_{2}}{\mathrm{H}}}
\end{aligned}
$$$$
K_{\mathrm{ADE}}=0.0023
$$$$
K_{\text {PRPP }}=0.0195
$$$$
K_{\mathrm{1}}=3.981 \cdot 10^{-5}
$$$$
K_{2}=3.162 \cdot 10^{-7}
$$

IMPase

(Heppel, 1951)

$$
\begin{array}{r}
v=\frac{K_{\mathrm{IMP}}}{1+\mathrm{INO} / K_{\mathrm{INO}}} \\
K=\frac{0.09387}{1+\frac{\mathrm{H}}{K_{1}}+\frac{K_{2}}{\mathrm{H}}}
\end{array}
$$

$$
\begin{aligned}
& K_{1}=2.5642 \cdot 10^{-3} \\
& K_{2}=1.2159 \cdot 10^{-6} \\
& K_{\mathrm{INO}}=25.0
\end{aligned}
$$


TABLE 9 (continued)

\begin{tabular}{|c|c|c|}
\hline Enzyme & Rate expression & Parameter values \\
\hline PRPP synthethase & $V=V_{m} V_{r} \frac{\mathrm{R} 5 \mathrm{P} \text { ATP }-\mathrm{PRPP} \mathrm{AMP} / K_{e q}}{N}$ & $K_{\mathrm{ATP}}=0.17$ \\
\hline \multirow[t]{2}{*}{ (DeVerdier, 1963) } & $V_{m}=-\frac{K_{0}}{1+\frac{\mathrm{H}}{K_{1}}+\frac{K_{2}}{\mathrm{H}}}$ & $K_{\mathrm{R} 5 \mathrm{P}}=0.65$ \\
\hline & $\begin{array}{l}N=V_{r} K_{R 5 P} \mathrm{ATP}+V_{r} K_{\mathrm{ATP}} \mathrm{R} 5 \mathrm{P}+V_{m} K_{\mathrm{AMP}} \mathrm{PRPP} / K_{\mathrm{eq}} \\
+V_{m} K_{\mathrm{PRPP}} \mathrm{AMP} / K_{\mathrm{eq}}+V_{r} \mathrm{R} 5 \mathrm{P} \mathrm{ATP}+V_{m} \mathrm{PRPP} \\
\quad \mathrm{AMP} / K_{\mathrm{eq}} \\
V_{r}=V_{m} / K_{t}\end{array}$ & $\begin{array}{l}K_{\mathrm{eq}}=28.6 \\
K_{v^{\prime}}=7.5 \\
K_{\mathrm{PRPP}}=0.09 \\
K_{\mathrm{AMP}}=0.275 \\
K_{0}=0.836 \\
K_{1}=1.0099 \cdot 10^{-4} \\
K_{2}=1.8835 \cdot 10^{-6}\end{array}$ \\
\hline \multirow{2}{*}{ HGPRT } & PRPP $\quad \mathrm{HX}$ & \multirow[b]{2}{*}{$\begin{array}{l}V_{m}-0.2011 \\
K_{\mathrm{PRPP}}=0.005 \\
K_{\mathrm{HX}}=0.22\end{array}$} \\
\hline & $l=v_{m} \overline{K_{\mathrm{PRPP}}}+\mathrm{PRPP} \overline{K_{\mathrm{HX}}+\mathrm{HX}}$ & \\
\hline
\end{tabular}

must be the same number of positive ionic charges in solution as there are negative charges.

$$
\begin{aligned}
& \sum_{j=1}^{n} z_{i j} C_{i j}=0 \\
& \sum_{j=1}^{n} z_{e j} C_{e j}=0
\end{aligned}
$$

where $z_{i j}$ and $z_{e j}$ represent the charges on intracellular and extracellular ions. With physiological ATP level, $\mathrm{H}^{+} / \mathrm{Cl}^{-}$and $\mathrm{H}^{+} / \mathrm{HCO}_{3}^{-}$ion pairs transport is much faster than other ion pairs $[14,15]$. The instantaneous cell volume change due to $\mathrm{pH}$ variation is then a result of fast $\mathrm{HCl}$ and $\mathrm{H}_{2} \mathrm{CO}_{3}$ transport. The intracellular $\mathrm{H}^{+}$concentration is buffered mostly by hemoglobin molecular, of which the dissociable functional groups concentration is the most abundant among all molecules in the red cell. Therefore, the primary source of intracellular hydrogen ions is hemoglobin molecules. Accordingly, two reac- tions are involved in the volume variation process when the cell is subjected to different $\mathrm{pH}$ media: the diassociation of hemoglobin and the cotransport of hydrogen ion and anions.

$$
\begin{aligned}
& \mathrm{H}-\mathrm{Hb} \rightleftharpoons \mathrm{Hb}^{-}+\mathrm{H}_{\mathrm{in}}^{+} \\
& \mathrm{H}_{\mathrm{in}}^{+}+\mathrm{An}_{\mathrm{in}}^{-} \rightleftharpoons \mathrm{H}_{\mathrm{ex}}^{+}+\mathrm{An}_{\mathrm{ex}}^{-}
\end{aligned}
$$

Instantaneous cotransport of $\mathrm{H}^{+}$and anions is assumed, and an equilibrium expression for the reversible reactions, 12 and 13 , can be written as follows:

$$
\frac{(\mathrm{Hb}+x) \mathrm{H}_{e} \mathrm{An}_{e}}{(\mathrm{HHb}-x)\left(\mathrm{An}_{i}-y\right)}=K_{e} e^{-Z F \Delta \Psi / R T}
$$

where $x$ is the moles of hemoglobin disassociated after a perturbation, $y$ is the number of $\mathrm{H}^{+}$/anions pairs transported through the membrane after the perturbation, $R$ is the ideal gas constant, $T$ is the temperature, $K_{e}$ is the disassociation constant of the functional group on hemoglobin molecule, $Z$ is the charge on the ions, $F$ is the faraday constant, $\Delta \Psi$ is the membrane potential, 
subscripts $i$ and $e$ represent the initial intra- and extra-cellular conditions. It can be assumed that $x$ is approxmately equal to $y$ since $\left[\mathrm{An}_{i}\right] \gg\left[\mathrm{H}_{i}\right]$, and can be solved by Eqn. 14 .

\section{6. $M g$ complexation}

Free $\mathrm{Mg}$ forms complexes with ATP, ADP, AMP, 23DPG, and their hydrogenated molecules.

\section{TABLE 10}

The rate expressions used to describe the kinetics of membrane transport processes considered in this model [11]

The unit for a concentration is $\mathrm{mM}$, and the unit for a reaction rate is $\mathrm{mM} / \mathrm{h}$. The references shown are for the $\mathrm{pH}$ dependence of kinetic constants.

\begin{tabular}{|c|c|c|}
\hline Transport & Expression & Parameter values \\
\hline \multicolumn{3}{|l|}{ Passive Na flux } \\
\hline (Harris, 1954) & $\begin{array}{l}l=K_{x} \ln (r) \frac{\mathrm{Na}_{e}-r \mathrm{Na}_{i}}{r-1}+V_{\mathrm{m}}\left(\frac{\mathrm{Na}_{e}}{K_{m}+\mathrm{Na}_{e}}-\frac{r \mathrm{Na}_{i}}{K_{m}+r \mathrm{Na}_{i}}\right) \\
V_{m}=2.816(-1.16+0.3 \mathrm{PH}) \\
K_{x}=7.055 \cdot 10^{-3}(-1.16+0.3 \mathrm{PH})\end{array}$ & $K_{m}=21.0$ \\
\hline \multicolumn{3}{|l|}{ Passive $\mathrm{K}$ flux } \\
\hline (Harris, 1954) & $\begin{array}{l}\iota=K_{x} \ln (r) \frac{K_{e}-r K_{i}}{r-1}+V_{m}\left(\frac{K_{e}}{K_{m}+K_{e}}-\frac{r K_{i}}{K_{m}+r K_{i}}\right) \\
V_{m}=3.115(-1.16+0.3 \mathrm{PH}) \\
K_{x}=6.349 \cdot 10^{-3}(-1.16+0.3 \mathrm{PH})\end{array}$ & $K_{m}=4.0$ \\
\hline \multirow{2}{*}{\multicolumn{3}{|c|}{$\mathrm{Na} / \mathrm{K}$ pump }} \\
\hline & & \\
\hline & $V_{m}=\frac{3,4}{1+\frac{\mathrm{H}}{K_{a}}+\frac{K_{b}}{\mathrm{H}}}$ & $K_{\mathrm{ATP}}=0.764$ \\
\hline & & $\begin{array}{l}B_{1}=0.0617 \\
B_{2}=0.1328 \\
B_{3}=6.2672 \\
\frac{K_{2}}{K_{1}}=0.0082 \\
\frac{K_{3}}{K_{1}}=0.0501 \\
e \approx 0.7114 \epsilon=0.7114 \\
K_{a}=3.7342 \cdot 10^{-3} \\
K_{b}=8.2714 \cdot 10^{-7}\end{array}$ \\
\hline Pyruvate & $v=K\left(\mathrm{PYR}-\mathrm{PYR}_{e x t}\right)$ & $K=63.8$ \\
\hline Lactate & $v^{\prime}=K\left(\mathrm{LAC}-\mathrm{LAC}_{e \times t}\right)$ & $K=12.8$ \\
\hline Hypoxanthine & $v=P_{m} \mathrm{HX}+V_{m} \frac{\mathrm{n \Lambda}}{\mathrm{HX}+K_{\mathrm{HX}}}$ & $\begin{array}{l}P_{\mathrm{m}}=37.8 \\
V_{m}=151.6 \\
K_{\mathrm{HX}}=0.4\end{array}$ \\
\hline Adenine & $v=V_{m}\left(\frac{\mathrm{ADE}_{i}}{K_{m}+\mathrm{ADE}_{i}}-\frac{\mathrm{ADE}_{e}}{K_{m}+\mathrm{ADE}_{e}}\right)$ & $\begin{array}{l}V_{m}=90.0 \\
K_{m}=2.6\end{array}$ \\
\hline
\end{tabular}


These $\mathrm{Mg}$ complexes regulate several important glycolytic enzymes, such as HK, PFK, and PK. Let $\mathrm{AMP}_{T}, \mathrm{ADP}_{T}, \mathrm{ATP}_{T}$, and $2,3 \mathrm{DPG}_{T}$ denote the total amount of phosphorylated metabolites; AMP, ADP, ATP and 2,3DPG represent the total free amount of these metabolites; and MgAMP, MgADP, MgHADP, MgATP, MgHATP and $\mathrm{Mg} 23 \mathrm{DPG}$ represent the corresponding magnesium complexes, then the equilibrium equations relating these concentration variables may be written as [16]:

$$
\begin{aligned}
& \frac{\left[\mathrm{MgATP}^{2-}\right]}{\left[\mathrm{Mg}^{2+}\right]\left[\mathrm{ATP}^{4-}\right]}=k_{b, \mathrm{ATP}}=1.39 \cdot 10^{4} \mathrm{M}^{-1} \\
& \frac{\left[\mathrm{MgHATP}^{1-}\right]}{\left[\mathrm{Mg}^{2+}\right]\left[\mathrm{HATP}^{3-}\right]}=k_{b, \mathrm{HATP}}=3.55 \cdot 10^{1} \mathrm{M}^{-1} \\
& \frac{\left[\mathrm{MgADP}^{-}\right]}{\left[\mathrm{Mg}^{2+}\right]\left[\mathrm{ADP}^{3-}\right]}=k_{b, \mathrm{ADP}}=1.32 \cdot 10^{3} \mathrm{M}^{-1} \\
& \frac{\left[\mathrm{MgHADP}^{0}\right]}{\left[\mathrm{Mg}^{2+}\right]\left[\mathrm{HADP}^{2-}\right]}=k_{b, \mathrm{HADP}}=3.24 \cdot 10^{1} \mathrm{M}^{-1} \\
& \frac{\left[\mathrm{MgAMP}^{0}\right]}{\left[\mathrm{Mg}^{2+}\right]\left[\mathrm{AMP}^{2-}\right]}=k_{b, \mathrm{AMP}}=6.01 \cdot 10^{1} \mathrm{M}^{-1} \\
& \frac{\left[{\left.\mathrm{Mg} 2,3 \mathrm{DPG}^{2-}\right]}_{\left[\mathrm{Mg}^{2+}\right]\left[2,3 \mathrm{DPG}^{4-}\right]}=k_{b, 2,3 \mathrm{GDP}}=5.98 \cdot 10^{2} \mathrm{M}^{-1}\right.}{}
\end{aligned}
$$

The disassociation constants for ATP, ADP, and AMP are [16]:

$$
\begin{aligned}
& \frac{\left[\mathrm{H}^{+}\right]\left[\mathrm{ATP}^{4-}\right]}{\left[\mathrm{HATP}^{3-}\right]}=k_{a, \mathrm{ATP}}=1.08 \cdot 10^{-7} \mathrm{M} \\
& \frac{\left[\mathrm{H}^{+}\right]\left[\mathrm{ADP}^{3-}\right]}{\left[\mathrm{HADP}^{2-}\right]}=k_{a, \mathrm{ADP}}=1.20 \cdot 10^{-7} \mathrm{M} \\
& \frac{\left[\mathrm{H}^{+}\right]\left[\mathrm{AMP}^{2-}\right]}{\left[\mathrm{HAMP}^{1-}\right]}=k_{a, \mathrm{AMP}}=3.24 \cdot 10^{-7} \mathrm{M}
\end{aligned}
$$

The corresponding mass conservation equations are:

$$
\begin{aligned}
& \mathrm{ATP}_{\mathrm{T}}=\mathrm{ATP}+\mathrm{HATP}+\mathrm{MgATP}+\mathrm{MgHATP} \\
& \mathrm{ADP}_{T}=\mathrm{ADP}+\mathrm{HADP}+\mathrm{MgADP}+\mathrm{MgHADP} \\
& \mathrm{AMP}_{T}=\mathrm{AMP}+\mathrm{HAMP}+\mathrm{MgAMP} \\
& 2,3 \mathrm{DPG}_{T}=2,3 \mathrm{DPPG}+\mathrm{Mg} 2,3 \mathrm{DPG} \\
& \mathrm{Mg}_{T}=\mathrm{Mg}+\mathrm{MgAMP}+\mathrm{MgADP}+\mathrm{MgATP} \\
& \quad+\mathrm{Mg} 2,3 \mathrm{DPG}
\end{aligned}
$$

Eq. (15-17) are the 14 set of equations with fourteen unknowns, where the unknowns are the free and the magnesium complexed metabolites. If the equilibrium constants are known $[8,16]$ and the total amount of adenosine phosphates and $2,3 \mathrm{DPG}$ is known (these variables are time dependent quantities in the dynamic model), this set of equations can be solved for the unknowns.

\subsection{Hemoglobin binding}

Hemoglobin molecule binds to ligands such as $\mathrm{O}_{2}, \mathrm{CO}_{2}, \mathrm{Cl}^{-}, 23 \mathrm{DPG}$, and $\mathrm{H}^{+}$. The binding affinity of a hemoglobin molecule to the ligands depends on the thermodynamic properties of the red cell plasma, e.g., the concentration of ligands.

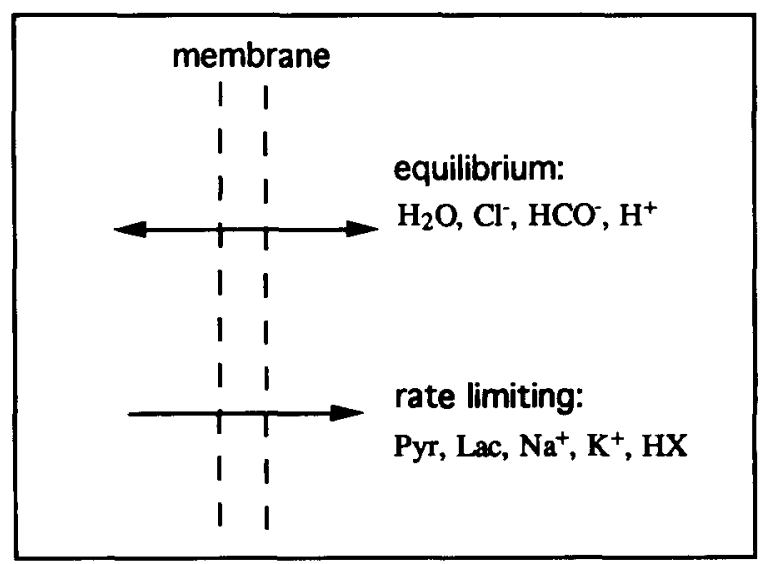

Fig. 2. Membrane transport processes can be separated into two groups: those which are fast and reach equilibrium; and those which are rate limiting. 
A 'state' of hemoglobin molecule is a specification of all the binding sites, together with a specification of quaternary structure of the molecule ( $T$ or $R$ ). The possibility of occurrence of a 'state' of the hemoglobin is proportional to the probability weight $W$ of the state. Given ligand concentrations, the partition function $P$ is the sum of the probability weights of all possible states. The partition function for hemoglobin binding can then be expressed as [17]:

$P=W_{H^{+}}\left(W_{R}+W_{T}\right)$

where $W_{\mathrm{H}^{+}}, W_{R}$, and $W_{T}$ can be further factorized:

$$
\begin{aligned}
W_{R}= & \left\{1+Q_{\mathrm{roxy}}\left[\mathrm{O}_{2}\right]\right\}^{4} \\
& \times\left\{1+Q_{\mathrm{rbh} 1}\left[\mathrm{H}^{+}\right]\left(1+Q_{\mathrm{rcl} 1}\left[\mathrm{Cl}^{-}\right]\right)\right. \\
& \left.+Q_{\mathrm{rcdx}} \frac{\left[\mathrm{CO}_{2}\right]}{\left[\mathrm{H}^{+}\right]}\right\}^{2} \\
& \times\left\{( 1 + Q _ { \beta \mathrm { atr } } [ \mathrm { H } ^ { + } ] ) ^ { 2 } \left(Q_{\mathrm{rbpg}}\left[23 \mathrm{DPG}^{5-}\right]\right.\right. \\
& +Q_{\mathrm{rbpg} 4}\left[23 \mathrm{DPGH}{ }^{4-}\right]+Q_{\mathrm{rbpg} 3}\left[23 \mathrm{DPGH}_{2}^{3-}\right] \\
& \left.+\left(1+Q_{\beta \mathrm{atr}}\left[\mathrm{H}^{+}\right]+Q_{\mathrm{rcdx}} \frac{\left[\mathrm{CO}_{2}\right]}{\left[\mathrm{H}^{+}\right]}\right)^{2}\right\} \\
& \left.+Q_{\mathrm{tcdx}} \frac{\left[\mathrm{CO}_{2}\right]}{\left[\mathrm{H}^{+}\right]}\right\}^{2} \\
& \times\left\{1+Q_{\mathrm{rbh} 2}\left[\mathrm{H}^{+}\right]\right\}^{4} \times\left\{1+Q_{\mathrm{rbh} 3}\left[\mathrm{H}^{+}\right]\right\}^{4} \\
& \times\left\{1+Q_{\mathrm{rcl} 2}\left[\mathrm{Cl}^{-}\right]\right\}^{2} \\
W_{\mathrm{T}}= & Q_{\mathrm{allo}} \times\left\{1+Q_{\mathrm{toxy}}\left[\mathrm{O}_{2}\right]\right\}^{4} \\
& \times\left\{1+Q_{\mathrm{tbh} 1}\left[\mathrm{H}^{+}\right]\left(1+Q_{\mathrm{tcl1}}\left[\mathrm{Cl}^{-}\right]\right)\right.
\end{aligned}
$$

$$
\begin{aligned}
\times & \left\{\left[( 1 + Q _ { \beta \mathrm { atr } } [ \mathrm { H } ^ { + } ] ) ^ { 2 } \left(Q_{\mathrm{tbpg} 5}\left[23 \mathrm{DPG}^{5-}\right]\right.\right.\right. \\
+ & Q_{\mathrm{tbpg} 4}\left[23 \mathrm{DPGH}^{4-}\right] \\
+ & Q_{\mathrm{tbpg} 3}\left[23 \mathrm{DPGH}_{2}^{3-}\right] \\
+ & \left.\left(1+Q_{\beta \mathrm{atr}}\left[\mathrm{H}^{+}\right]+Q_{\mathrm{tcdx}} \frac{\left[\mathrm{CO}_{2}\right]}{\left[\mathrm{H}^{+}\right]}\right)^{2}\right\} \\
\times & \left\{1+Q_{\mathrm{tbh} 2}\left[\mathrm{H}^{+}\right]\right\}^{4} \times\left\{1+Q_{\mathrm{tbh} 3}\left[\mathrm{H}^{+}\right]\right\}^{4} \\
& \left.\times\left\{1+Q_{\mathrm{tcl} 2}[\mathrm{Cl}]^{-}\right]\right\}^{2} \\
\mathrm{~W}_{\mathrm{H}}= & \left\{1+Q_{\mathrm{ctr}}\left[\mathrm{H}^{+}\right]\right\}^{4} \times\left\{1+Q_{\mathrm{hem}}\left[\mathrm{H}^{+}\right]\right\}^{8} \\
& \times\left\{1+Q_{\mathrm{glu}}\left[\mathrm{H}^{+}\right]\right\}^{54} \times\left\{1+Q_{\mathrm{his}}\left[\mathrm{H}^{+}\right]\right\}^{16} \\
& \times\left\{1+Q_{\mathrm{cys}}\left[\mathrm{H}^{+}\right]\right\}^{2} \times\left\{1+Q_{\mathrm{tyr}}\left[\mathrm{H}^{+}\right]\right\}^{8} \\
& \times\left\{1+Q_{\mathrm{lys}}\left[\mathrm{H}^{+}\right]\right\}^{44} \times\left\{1+Q_{\mathrm{arg}}\left[\mathrm{H}^{+}\right]\right\}^{12}
\end{aligned}
$$

The $Q$ s are the effective association constants for the various binding reactions [17]. The occupancy number of each ligand, which is defined as the average number of the ligand molecules bound to a hemoglobin molecule, can be calculated from Eqn. 18 as follows:

$Y_{l}=\frac{\mathrm{d} \ln P}{\mathrm{~d} \ln [l]}=\frac{[l]}{P} \frac{\mathrm{d} P}{\mathrm{~d}[l]}$

where $Y_{l}$ is the occupancy number of ligand, $l$, and can be easily calculated numerically or analytically by taking the derivative of Eqn. 18 .

\section{Program structure}

The ordinary differential equations and the algebraic equations describing the red blood cell, Eqns. 1-17, are solved using the ordinary differential equation integrator DEPISODE. This li- 

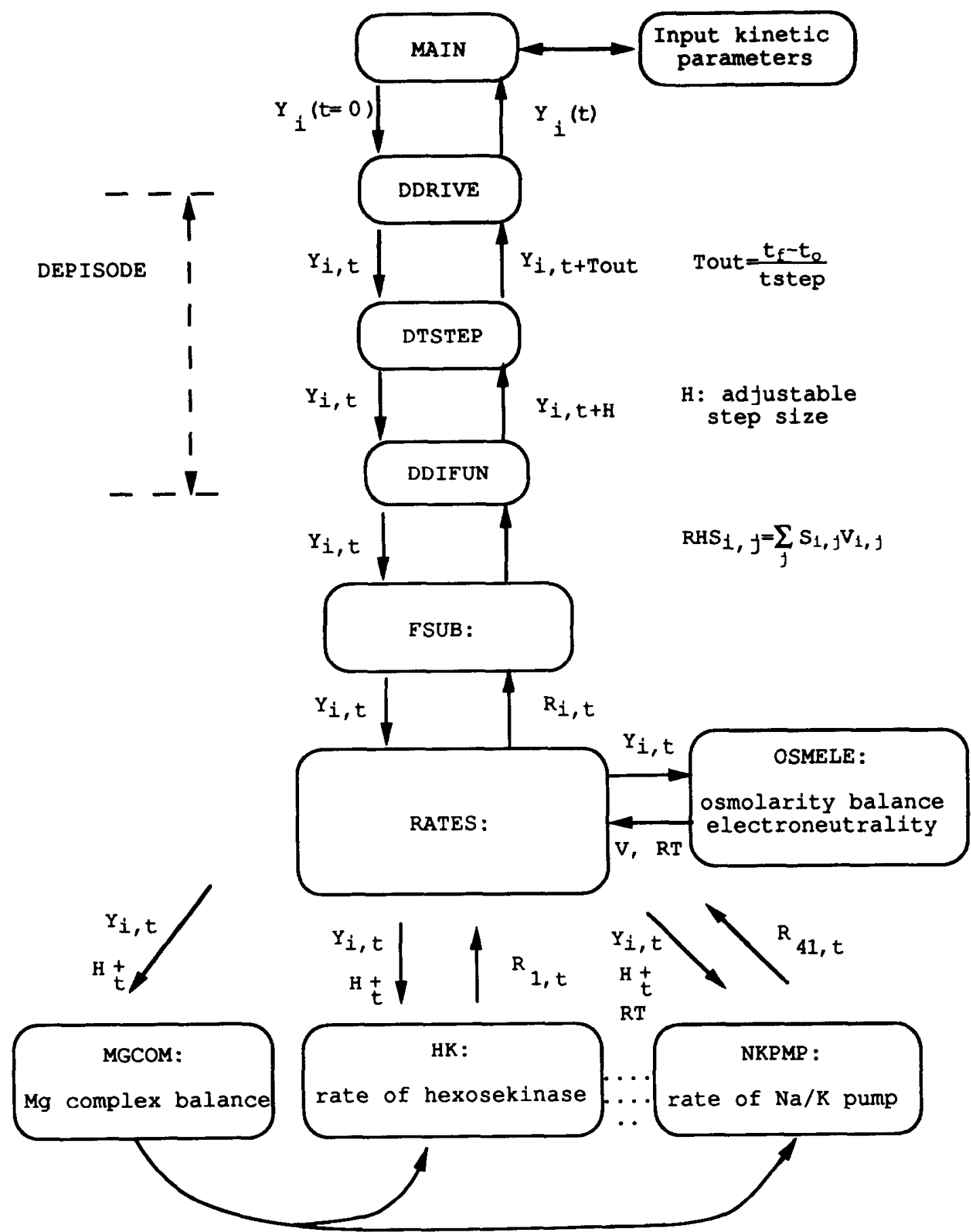

Mg complex

Fig. 3. The flow diagram of the computer simulator for human red blood cell. 
brary requires a user supplied subroutine, named FSUB, which receives the values of the time dependent variables at a particular point in time and calculates the time derivatives of the variables at that instant; i.e.,

$y$ at time $t \stackrel{\text { FSUB }}{\longrightarrow} \frac{\mathrm{d} y}{\mathrm{~d} t}$ at time $t$

Subroutine FSUB must thus calculate the reaction rate of each metabolic reaction given the metabolite concentrations, under the algebraic constraints imposed.

Since the time derivative are evaluated from

$$
\frac{\mathrm{d} y}{\mathrm{~d} t}=S \cdot v(y) V
$$

where $y$ corresponds to $V C$ in Eqn. 1 and $S$ is the stoichiometric matrix. One must evaluate the reaction rates from the concentration vector $y$ that is supplied. The subroutine FSUB calls a subroutine RATES, that calculates the metabolic reaction rates given the metabolite concentrations, before carrying out the matrix multiplication specified in Eqn. 24. RATES then in turn calls the subroutines for individual metabolic reaction rates. The parameters for each reaction rate kinetics can be altered through a menu driven format.

The reaction rate laws require concentration variables that are not any of the dynamic variables $y s$. These concentrations are calculated through the coupled algebraic equations. In addition, the electroneutrality and osmotic balance equations must be balanced by assigning the appropriate values to volume and Donnan ratio.

The sequence in which the calculations are carried out is; first, electroneutrality and osmolarity balance are satisfied by OSMELE, then magnesium complexes concentrations are evaluated by MGCOM, followed by the computation of individual reaction rates. Notice that all the fast processes are calculated before metabolic reaction rates because the formers are assumed to be at equilibrium at all times. Therefore, in each iteration of FSUB and RATES, all the three fast processes-electroneutrality, osmolarity balance, and magnesium complexation-will be satisfied before the slow metabolic reaction rates are calculated.

The flow diagram of the computer program is shown in Fig. 3. All the subroutines between the MAIN program and subroutine DDIFUN belong to the ODE solver DEPISODE, which integrates dependent variables $Y_{i}$ given derivatives RHS $_{i}$. The rest of the program takes $Y_{i}$, calculates $\mathrm{RHS}_{i}$, and return the derivatives to DEPISODE.

\section{Software package description}

The initial screen display of the Macintosh software package consists of a main menu and a diagram of the metabolic pathways of the red cells. The titles in the menu include 'command', 'glycolysis', 'pentose', 'nucleotide', 'steady', and 'integration'. The users can examine each enzyme kinetic equation and change parameter values in the kinetics by either choosing the enzyme under menu titles 'glycolysis', 'pentose', and 'nucleotide', or by clicking the enzyme in the diagram of the metabolic pathways. Either way, the kinetic equations for the selected enzyme will show up in a new window, and one can decide to vary the kinetic parameters by reading them from a data file. To read the data file storing the new parameter values, the user can select item 'read file' under menu title 'read parameter'. The name of the data file must not contain any space and symbol except period ' $\therefore$ In the data file the parameter values must be in the same sequence as those appeared on the screen, and a 'return' key must be used after the last data entry to serve as the 'end of file' command. To go back to the main menu after viewing kinetic equations, the user can select item 'done' under menu title 'command'.

The user can choose to calculate steady state metabolite concentrations by selecting item 'steady state' under title 'steady' from the main menu. When calculating the steady state solution, the package uses the Newton's routine and reads the initial guess from the default data file 'ss.dat'. The data in 'ss.dat' are in the following order: number of equations, the concentrations of 33 
metabolites listed in Table 1, the accuracy of the calculation, and the allowable maximum iteration for the Newton's method. The user can input new initial guess from another data file by selecting menu item 'read guess values' under the same menu title. To calculate the steady state solution, simply select item 'steady state', where the steady state solution will be calculated and saved in the text file 'steady-filename', where 'filename' is the file containing the guess values ('ss.dat' in default). The format of the steady state solution output file is the 33 metabolite concentrations in the same order as in Table 1.

To determine the response of the red cell metabolism to a perturbation, the user can select item 'integrate' under menu title 'integration' of the main menu. The perturbation can be specified in data files 'integrate.dat' and 'initial.dat'. The data in 'integrate.dat' are: the number of metabolites, the concentrations of the metabolites listed in Table 1 , the initial time, the final time of integration, the number of outputs between the initial and final time, and the relative accuracy of the calculation. The initial values of metabolite concentrations for integration can also be read interactively by choosing menu item 'read initial value' from menu title 'integration'. The data in 'initial.dat' are: osmolarity, concentrations of glucose, adenine, carbon dioxide, total glutathione, extracellular lactate, total magnesium, total NADH, $P_{i}, P P_{i}$, extracellular pyruvate, hemoglobin, and extracellular $\mathrm{pH}$. The integrated metabolite concentrations are saved in file 'concentration-filename', and the metabolite fluxes are saved in file 'flux-filename', where 'filename' is the file containing the initial conditions for integration. The output files contain the integration results at various time. It shows the number of printout, the time for integration, and 33 concentrations in Table 1, 41 fluxes in Table 2, cell volume, Donnan ratio, $\mathrm{Mg}$ complexes, and hemoglobin binding coefficience. After completing the integration, metabolite concentrations or fluxes can be plotted against time by selecting items 'concentration' or 'flux' under the same menu title. If the formats of integration output files 'cmpd.out' and 'rates.out' are incorrected or altered for some reasons, errors will occur while the simulator is reading the files before plotting. The output files of integration, 'flux-filename' and 'concentration-filename', can also be read by commercial plotting packages such as Cricket $\mathrm{Graph}^{\mathrm{TM}}$. When using a plotting routine, the user should delete the first row of each output file, which is the variable names, and specify the data format as numerical instead of alphabetic.

The response of the red cell metabolism can be calculated with the external $\mathrm{pH}$, osmolarity glucose, adenine, phosphate, and lactate concentrations as functions of time. Two types of timedependent functions are available in the menu 'integration', linear and step wave. The user can choose the desired time-dependent perturbation of external parameters, and key in the slope and interception for the linear functions, or period and altitude for the step wave functions. The calculation time may vary among cases, depending on the time variation functions. A large change of external parameter creates a stiff numerical problem, and it will take a longer time to integrate such a problem, especially around the discontinuous points of the step wave functions. The user may want to be careful not to give the perturbation functions negative values or unreasonable deviation from the physiological conditions. The stage of integration will be indicated on the screen, and the user can stop the calculation by clicking the 'cancel' box several times.

The user can also examine each enzyme activity as functions of several parameters by selecting item 'enzyme vs parameter' under menu title 'command' from the main menu. Once the item is selected, a new set of menu appears. The user must first choose one parameter under menu title 'parameter', and one enzyme under menu titles, 'fast process', 'glycolysis', 'pentose', or 'nucleotide', before selecting 'calculate response' under 'commands' to calculate the chosen enzyme activity as a function of the chosen parameter. The results that show the activity or corresponding metabolite concentrations of the selected enzyme as function of the selected parameter will be plotted on the screen.

The hemoglobin binding curves can be calculated and plotted as functions of ligand concentrations by selecting menu item 'hemoglobin 
binding' under menu title 'command'. All the ligand concentrations will remain constant except one of them, which will be assigned a maximum and minimum value by the user. The physiological ligand concentrations will show up on the screen as the reference. The user can choose to change any of them. Then the user will assign the range of one ligand by selecting the ligand and key in the maximum and minimum values. After the calculation, the user can examine the hemoglobin binding curves by selecting the curves of interest.

\section{Sample calculations}

This section provides several examples for calculating steady state solution, varying enzyme ki- netic parameters, integrating the equations, plotting the integration results, and examining enzyme activities as function of some parameters. The users can follow the format of the data file provided here, but it is not necessary to use exactly the same numerical values in these examples. All the data files must be in the same folder as the simulator.

\subsection{Steady state solution}

After the program is open, the screen will display the main menu and the red blood cell metabolic pathways. The user can examine different parts of the pathways by ciicking the scroll bar on the side of the window:

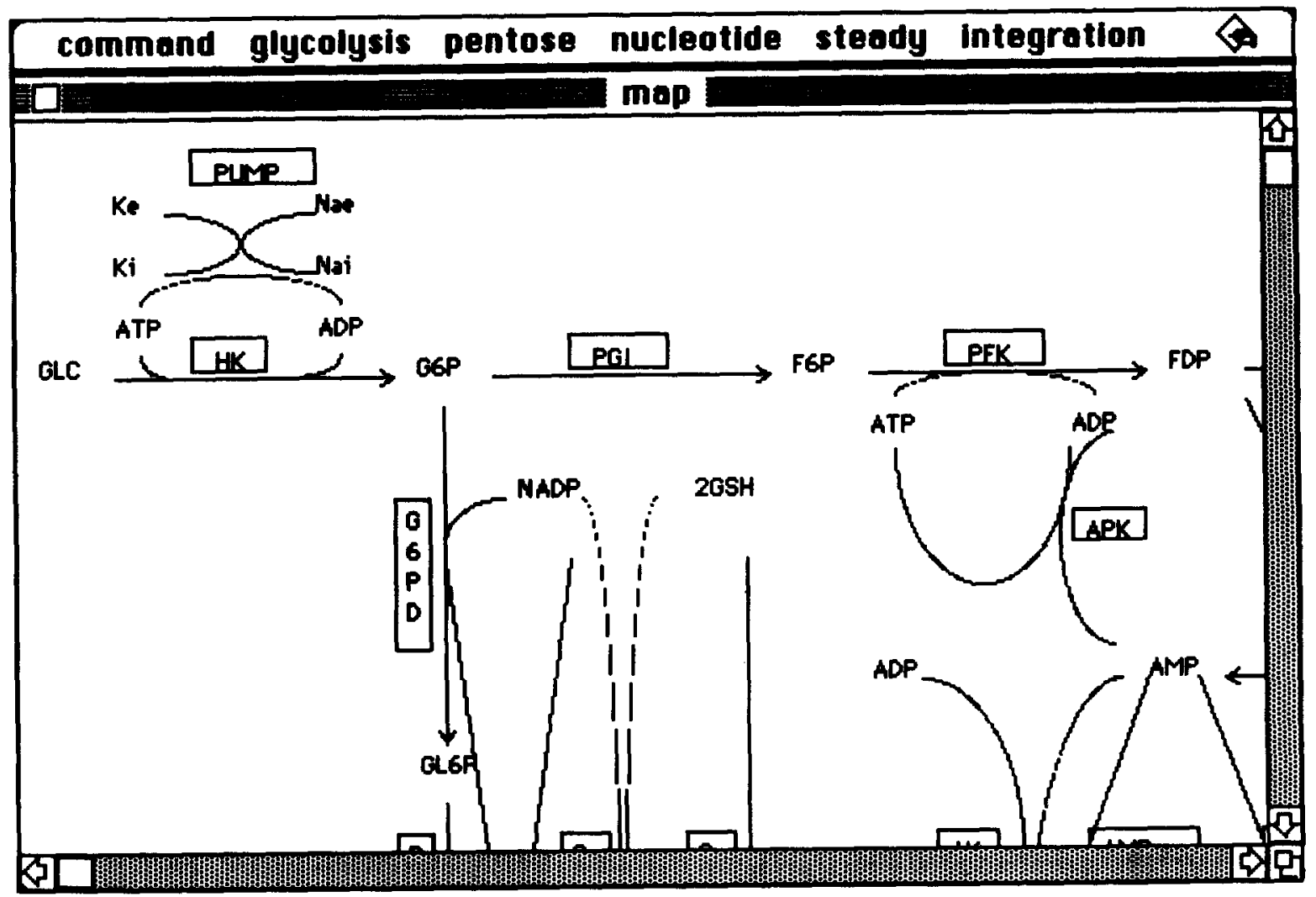


To calculate steady state solution, one must prepare data files 'ss.dat', which contains the initial guess for the steady state solution. The user can create the file before running the program or while running the program using the multifinder. When using the multifinder, 0.5-1.0 MB of RAM memory must be available to the simulator. The format of file 'ss.dat' is specified in the last section of this paper, and the following is an example:

33

$$
\begin{array}{ll}
.0783238742586310 & \text { GGP } \\
.0214515424943221 & \text { FGP } \\
.0110302900135918 & \text { FDP } \\
.0059496964255317 & \text { DHAP } \\
.0001916107266366 & \text { 13DPG } \\
.0957289306390129 & \text { PG } \\
.0140049424819202 & \text { PG } \\
.0238447437954066 & \text { PEP } \\
.0603541704974423 & \text { PYR } \\
1.3991010827880620 & \text { LAC } \\
4.1222154428310130 & 23 D P G \\
.0299475245109086 & \text { NADH } \\
.0009572218971675 & \text { A } \\
.1501073286614772 & \text { AMP } \\
.4063990004142602 & \text { ADP } \\
1.8845034363260600 & \text { ATP } \\
.0000115981447486 & \text { GL6P } \\
.3180532944225540 & \text { GO6P } \\
.0000960091929303 & \text { NADP } \\
3.3197885261668740 & \text { GSH } \\
.0128078773366617 & \text { RUSP } \\
.0328272857613718 & \text { R5P } \\
.0384030233978555 & \text { X5P } \\
.2229783139471450 & \text { S7P } \\
.0005173914906233 & \text { E4P } \\
.0115810568214895 & \text { PRPP } \\
.0180291502069131 & \text { IMP } \\
.0000141149174815 & \text { INO } \\
.0000571424463841 & \text { HX } \\
.0030220580129635 & \text { R 1P } \\
149.6365524269620000 & \text { KI } \\
12.0280444984959300 & \text { NAI } \\
1.00-8 & \\
1000 & \\
\hline
\end{array}
$$

Data file 'initial.dat', the content of which is specified in the last section, is also required for the calculation of steady state solution:

300.0 OSM

$5.000 \mathrm{GLC}$

$0.013 \mathrm{ADE}$

$1.200 \mathrm{CO}_{2}$

3.320 GSSG t

1.200 LACEXt

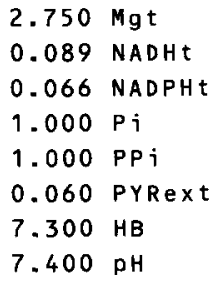

A file containing the names of metabolites, 'cnames.dat', is also needed.

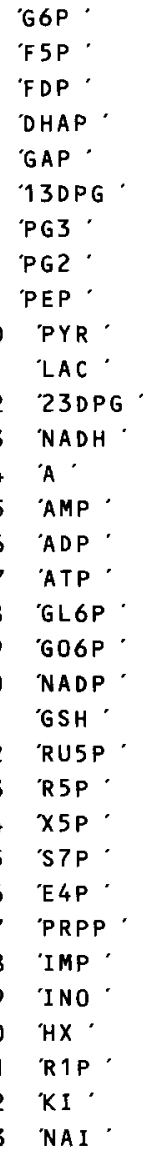

To read the initial guess for the steady state solutions, choose item 'read guess values' under menu title 'steady' and open the data file 'ss.dat'.

The ideal initial guess will be the steady state solution for a set of conditions and parameters similar to the current ones. The simulator applies Newton's method to search for the solution; therefore, a bad initial guess may not converge to the true solution. Finally, choose item 'steady state' to calculate the solutions, which will be writen into the output file 'steady-ss.dat'. 


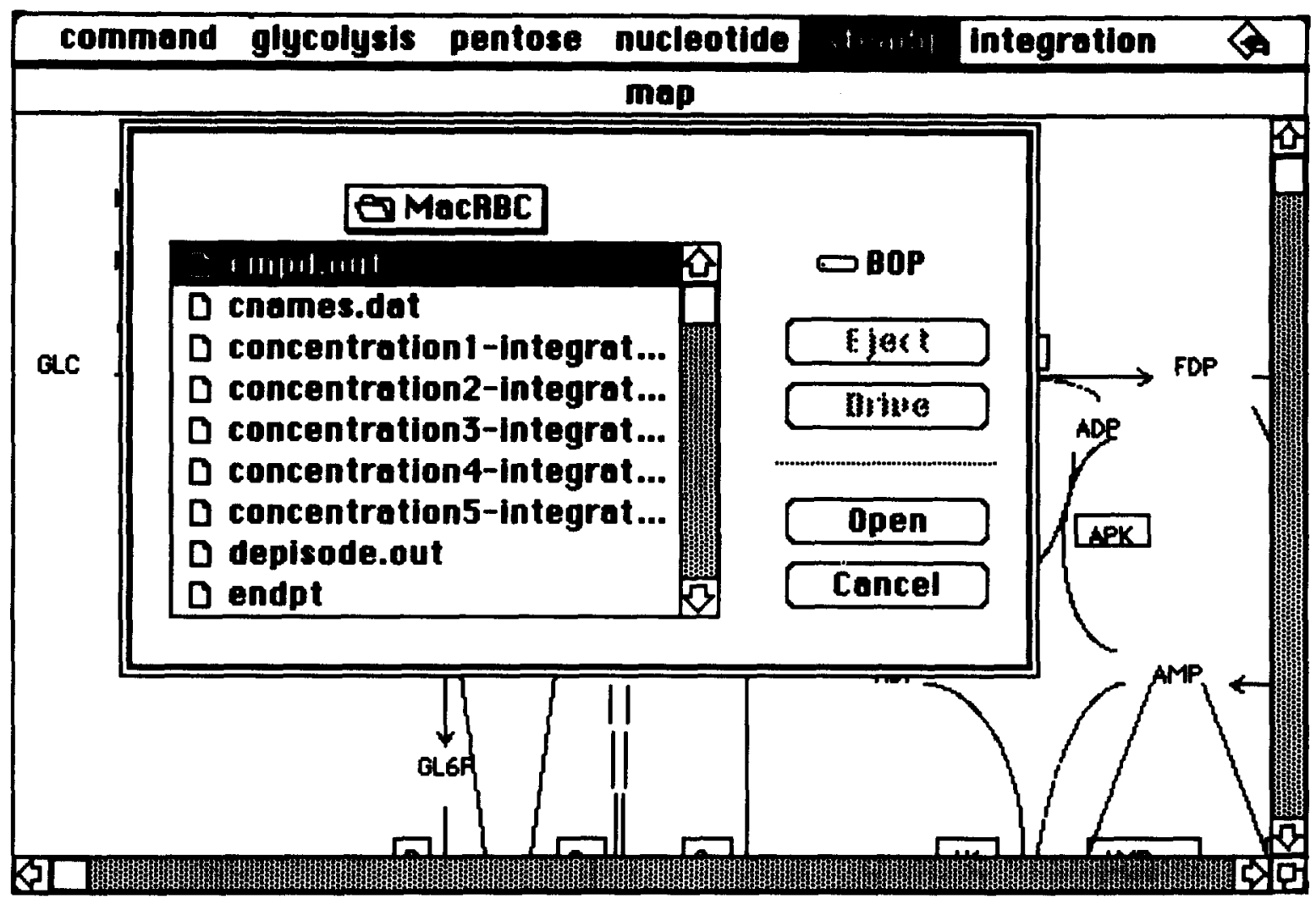

\subsection{Vary enzyme kinetic parameter}

To vary enzyme kinetic parameters, one needs a data file that contains a new set of kinetic parameters for the enzyme of interest. The data file can be prepared using multifinder while running the simulator. In the following example, the parameters Vmax for hexokinase is changed from 7.5095 to 8.0 and saved in file 'hk.dat':

0.051

1.13

1.14

0.04

0.069

1.03

2.7

3.44

$2.2718 \mathrm{e}-4$

$4.6015 e-6$

8.0

1.55

To read the new parameters, click the box for hexokinase in the metabolic pathway and the following screen will appear. On the left of the screen is the reaction, and on the right list the kinetic parameters. The new kinetic parameters in the data file must be in the same order as those shown on the screen.

To change the parameters, choose the item 'read file' under menu title 'read parameter' and open file 'hk.dat'. Follow the procedure for steady state calculation and use 'ss.dat' as the initial guess. The steady state solutions for the new set of kinetic parameters will be saved in file 'steadyss.dat' and 'hb.output':

$$
\begin{aligned}
& \text { steady-ss.dat: } \\
& .1071688406618640 \text { G6P } \\
& .0180563312421778 \text { F6P } \\
& .0105257324589483 \text { FDP } \\
& .1279397424648304 \text { DHAP } \\
& .0057975508688860 \text { GAP } \\
& .0001862371033082 \text { 13DPG } \\
& .0972614502612578 \text { PG3 } \\
& .0142300487685762 \text { PG2 } \\
& .0242290453796189 \text { PEP } \\
& .0602856809418147 \text { PYR }
\end{aligned}
$$




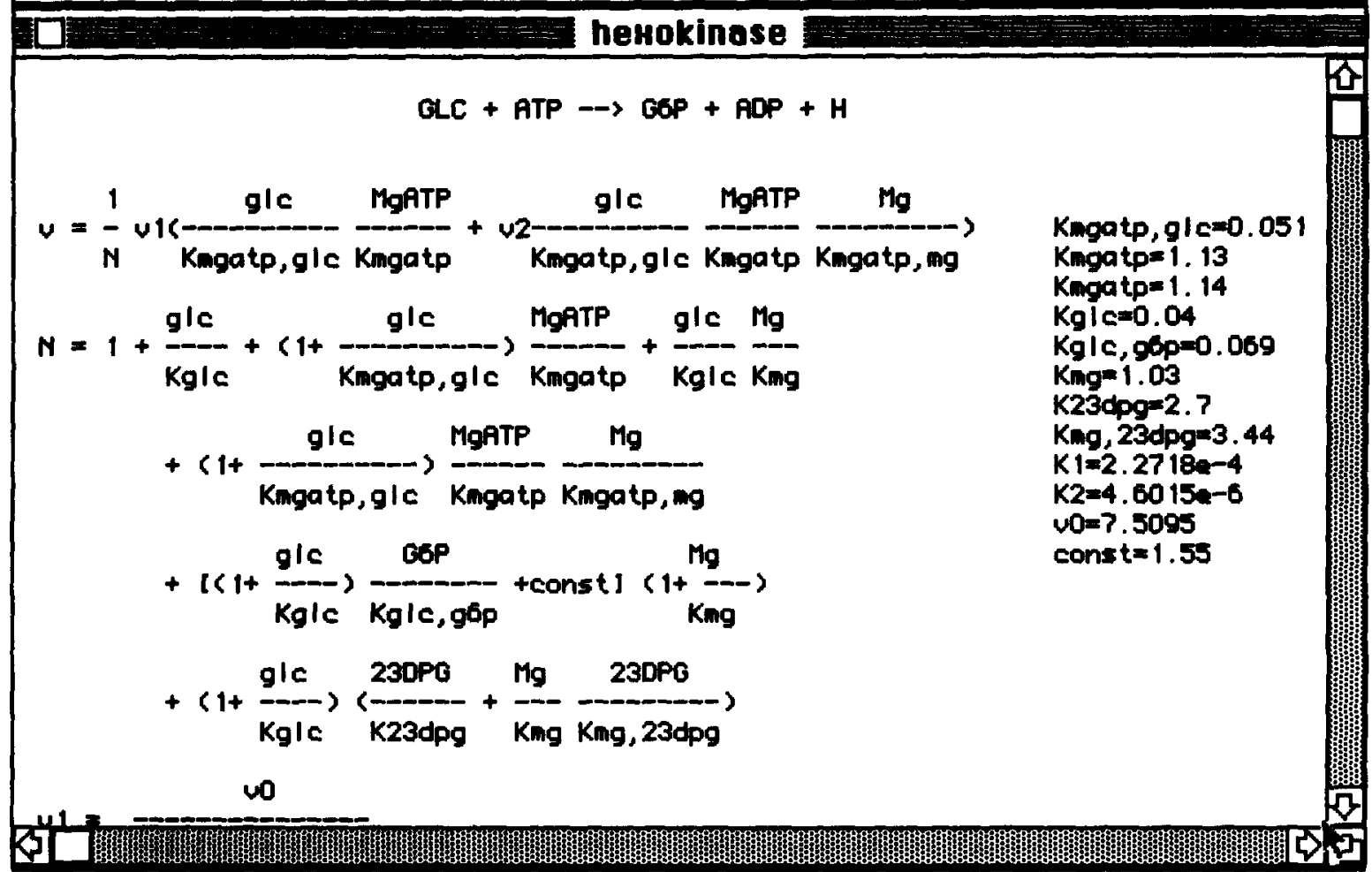

1.3984278719500000 LAC

4.0026708644642500 23DPG

$.0299296384356291 \mathrm{NADH}$

.0000616672610864 A

.1602156496303170 AMP

.4173848958312820 ADP

1.8698469281846000 ATP

.0000115993616484 GL6P

.4061808271702221 GD6P

.0000860942036754 NADP

3.3197886122968200 GSH

.0138574472908608 RU5P

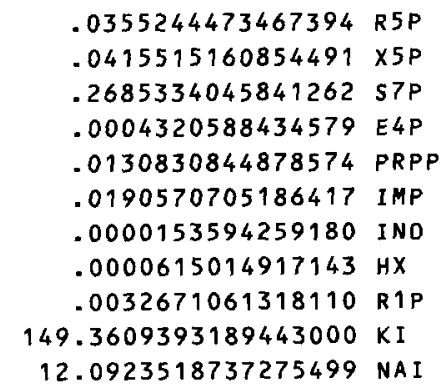

hb.output:
temp
[02]
[co2]
[232bpgtot] [h]
[C1]

$3.1000 \mathrm{E}+02 \quad 1.000 \mathrm{E}-03 \quad 1.2000 \mathrm{E}-03 \quad 4.1222 \mathrm{E}-03$ total fixed charge per hb molecule

$-1.4909 \mathrm{E}+00$

$y$ hy $=78.24$ yoz $=4.00$ ycoz= .47 ybpg $=.43$ ybpg $4=0.00$ ybpg $3=.40$ ycl $=.37$ 


\subsection{Integration}

To integrate and obtain the dynamic solutions, one must provide the initial conditions for the integration, for example 'integrate.dat':

33

$$
\begin{aligned}
& .0783238742586310 \text { G6P } \\
& .0214515424943221 \text { F6P } \\
& .0110302900135918 \text { FDP } \\
& .1312854805868560 \text { DHAP } \\
& .0059496964255317 \mathrm{GAP} \\
& .0001916107266366 \text { 13DPG } \\
& .0957289306380129 \text { PG } 3 \\
& .0140048424819202 \text { PG2 } \\
& .0238447437954066 \text { PEP } \\
& .0603651704974423 \text { PYR } \\
& 1.3991010827880620 \text { LAC } \\
& 4.122215442831013023 D P G \\
& .0299475245109086 \mathrm{NADH} \\
& .0000572218971675 \text { A } \\
& .1501073286614772 \text { AMP } \\
& .4063990004142602 \text { ADP } \\
& 1.8845034363260600 \text { ATP } \\
& .0000115981447486 \text { GL6P }
\end{aligned}
$$

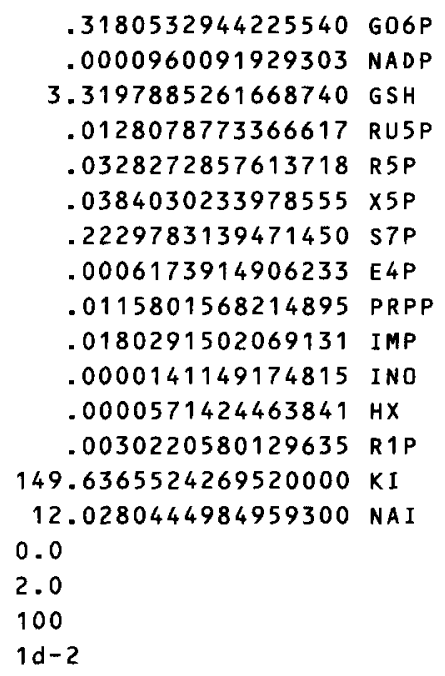

The user can also assign perturbation on $\mathrm{pH}$, osmolarity, and other conditions to the red cell by changing the data file 'initial.dat'. After 'integrate.dat' is edited, choose item 'read initial value' under mean title 'integrate' to read the initial conditions. Then choose one of the time-dependent functions of external parameter under menu title 'integrate', for example, 'pH wave', and key in the period and altitude of the wave function as follows:

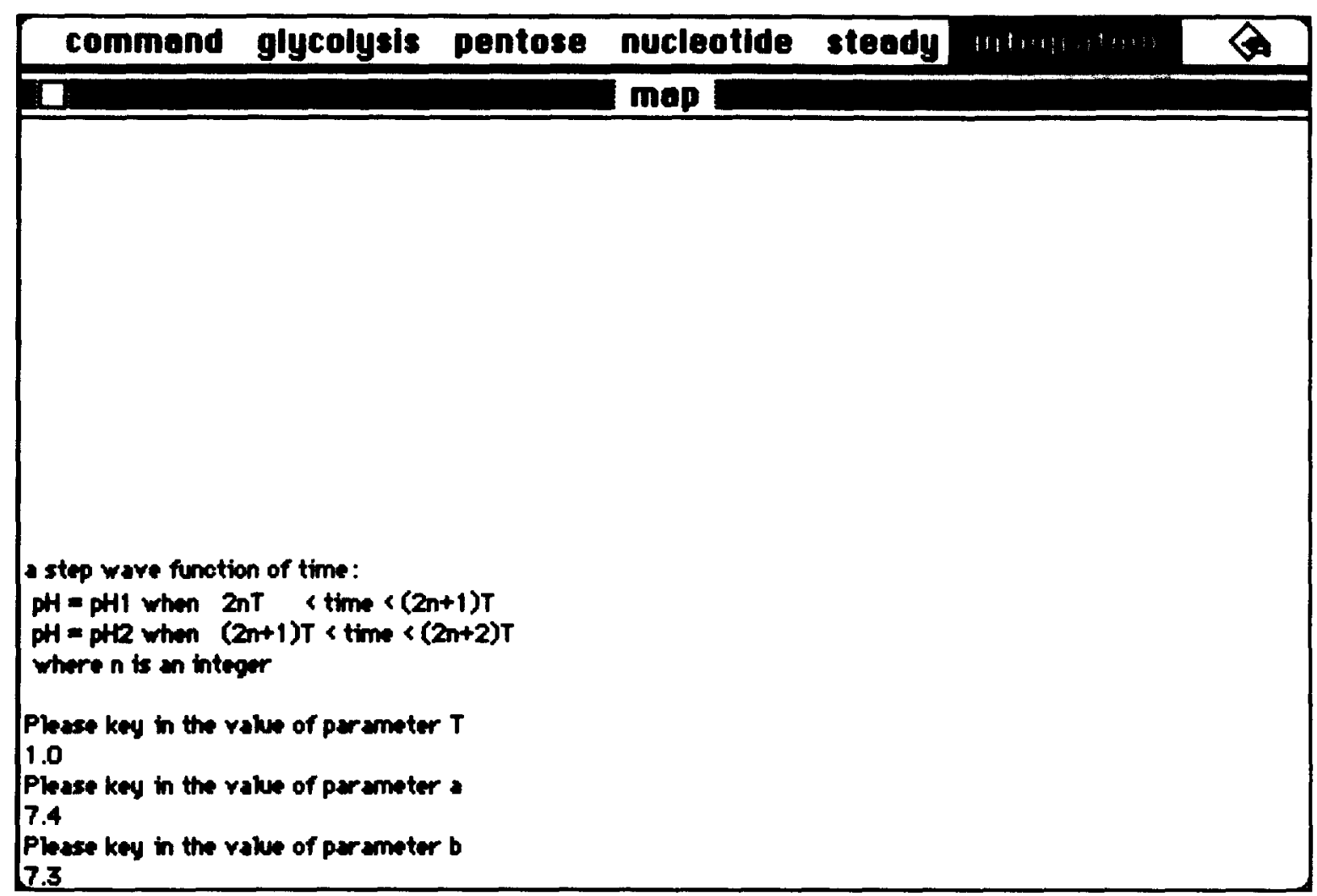




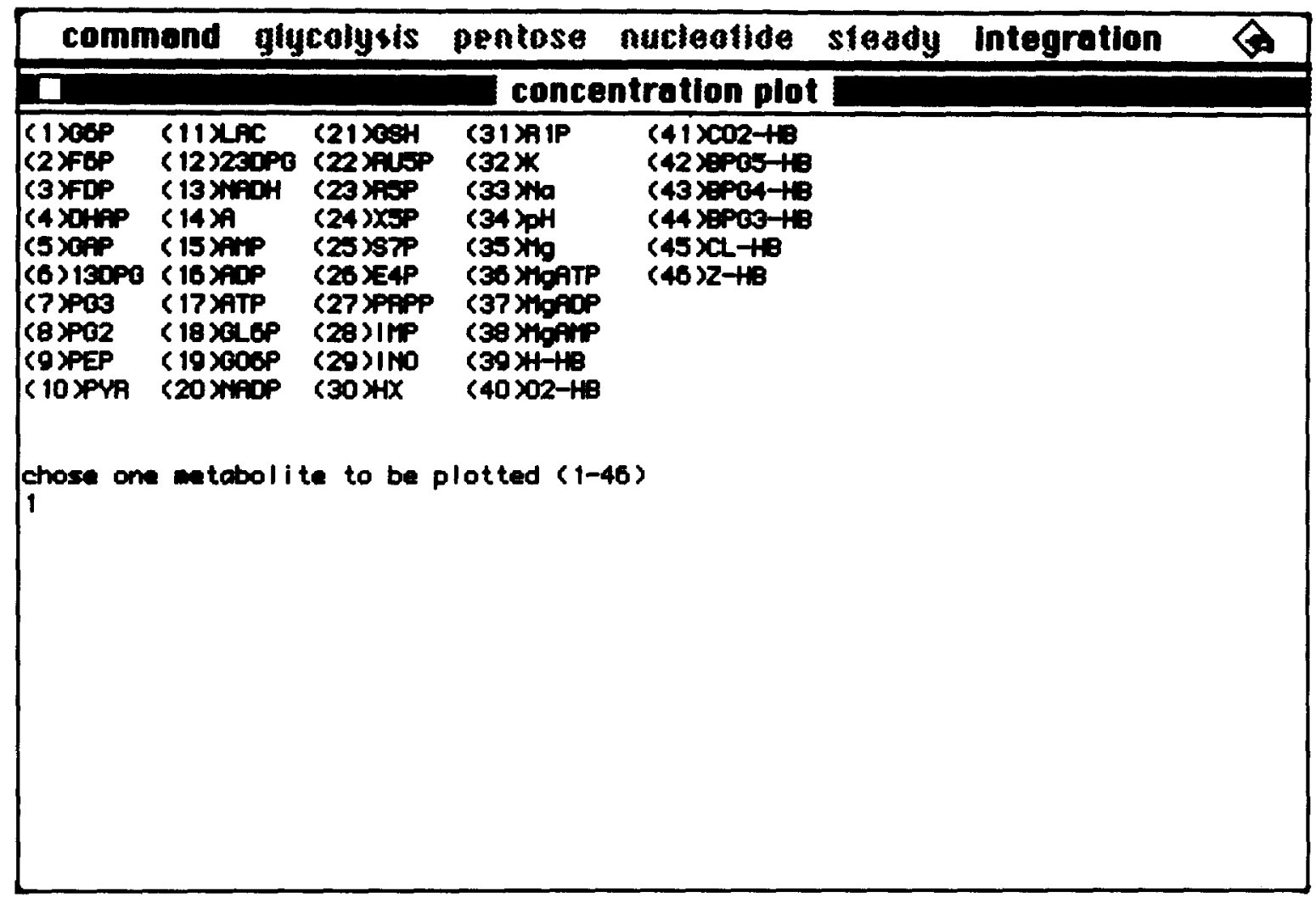

For example, choose 1 to plot G6P concentration as a function of time. The plot will be shown on the screen as follows.

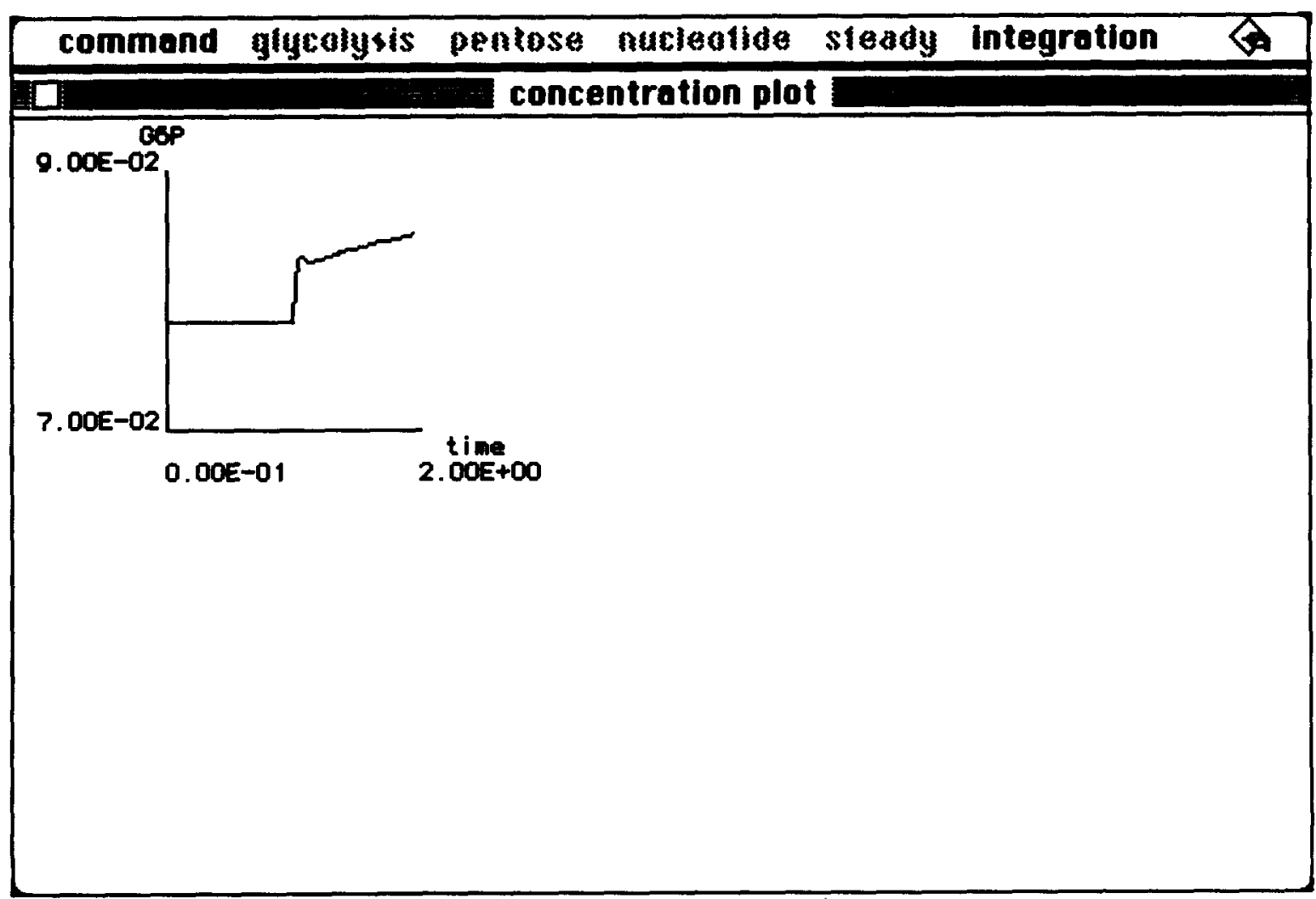


More sophisticated plots may be obtained by reading and reformating the output files from other graphic software packages.

\subsection{Enzyme activity us parameter}

To calculate enzyme activity as a function of a parameter, simply choose item 'enzyme vs parameter' under menu title 'command'. However, this calculation can be performed only after a steady state solution is obtained, since the calculation is based on the reference metabolite concentrations given in 'steady-ss.dat' or whatever file containing the steady state solutions. Choose the parameter under 'parameter' and give the range of the parameter. For example, $\mathrm{pH}$ :

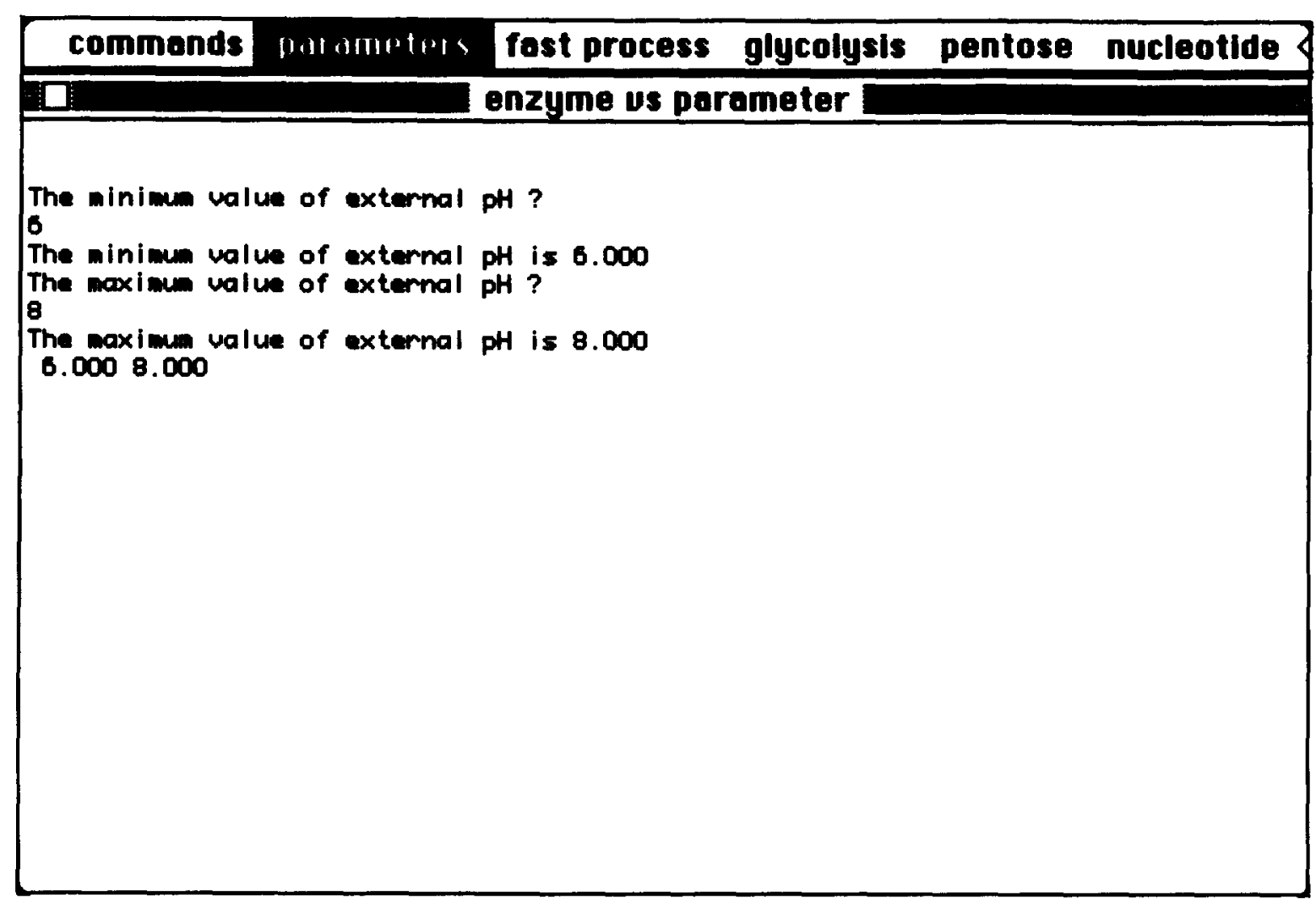

Then select one of the processes or enzyme fluxes under 'fast process', 'glycolysis', 'pentose', or 'nucleotide'. To see the correlation, choose 'calculate response' under menu title 'commands' and the 
results will be plotted on the screen. The following are $\mathrm{Mg}$ complexes as functions of $\mathrm{pH}$ varying from 6.0 to 8.0 :

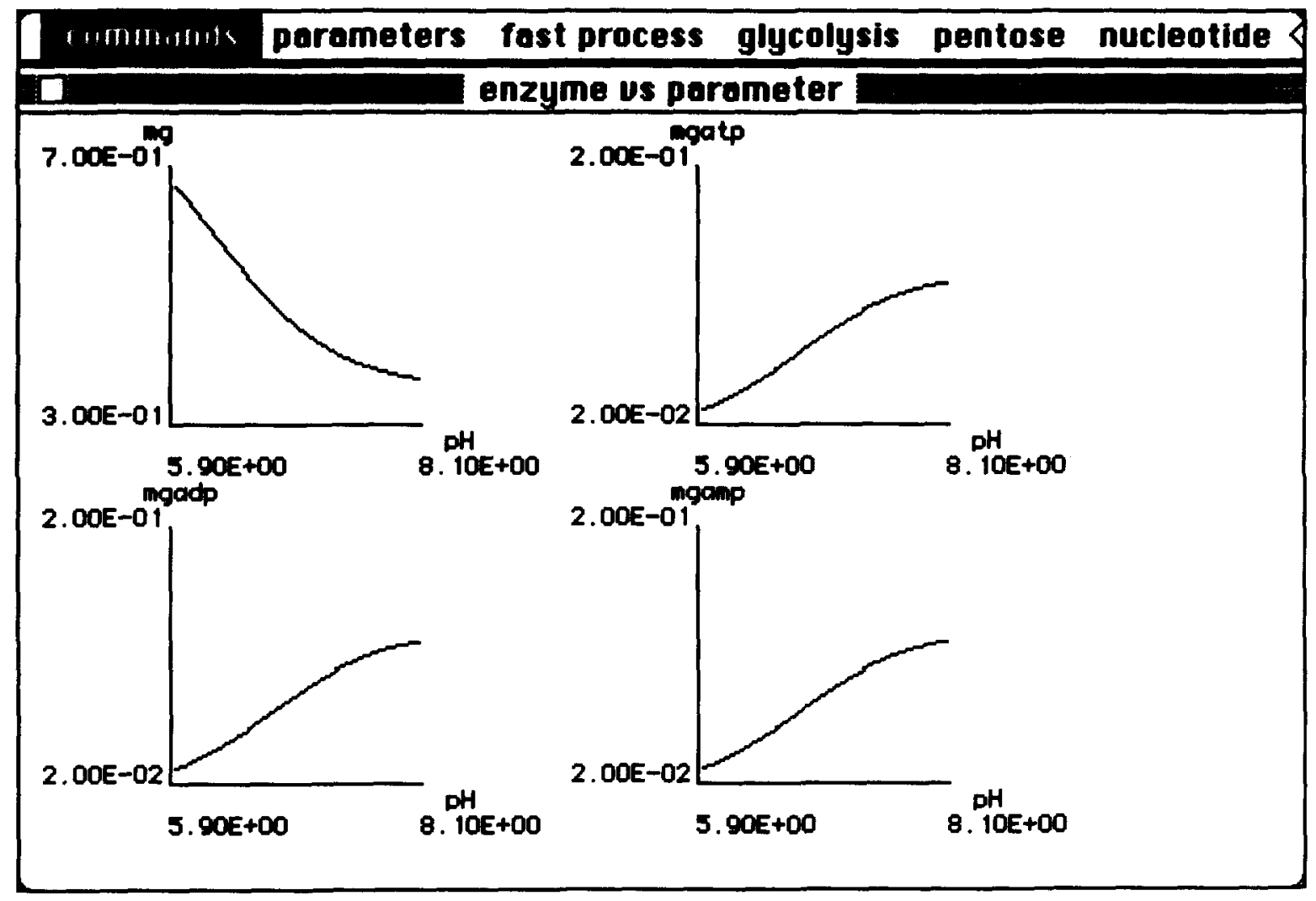

\subsection{Hemoglobin binding curve}

To calculate the hemoglobin binding curves, choose 'hemoglobin binding' under 'command', and a list of reference ligand concentrations will appear. Change the reference ligand concentrations by typing the corresponding number and keying in the new concentration, or type 8 to continue to next step. 
Then select the variable ligand concentration and give the maximum and minimum values. In the above example, $\mathrm{pH}$ is varied from 5 to 9 . After a few seconds of calculation, the following will show up on the screen:

\section{command glycolysis pentose nucleotide steady integration}

The reference 1 igand concentration are:

$\begin{array}{lll}\text { (1) TEMPERATURE }=310 \mathrm{C} & \text { (2) IONIC STRENGTH }=0.15 \mathrm{M}\end{array}$

(3) $\mathrm{PH}=7.2$

(4) $02=0.001 \mathrm{M}$

(5) $\mathrm{CO2}=0.0012 \mathrm{M}$

(6) $230 P G=0.004 M$

(7) $C L=0.08 \mathrm{M}$

(8) NO CHANGE

(9) exit

Change a reference I igond concentration?

8

please choose the variable paraneter

(1) TEMPERATURE (2) IONIC STREMGTH

$\begin{array}{ll}\text { (3) } \mathrm{PH} & \text { (4) } 02\end{array}$

$\begin{array}{ll}\text { (5) } \mathrm{CO2} & \text { (6) } 230 \mathrm{PG}\end{array}$

$\begin{array}{ll}\text { (7) } \mathrm{CL} & \text { (8) exit }\end{array}$

3

please type the range of the parameter

the maximum = ?

5

the minimum = ?

0 
Type 4 to plot $23 \mathrm{DPG}^{5-}$ binding coefficience as a function of $\mathrm{pH}$

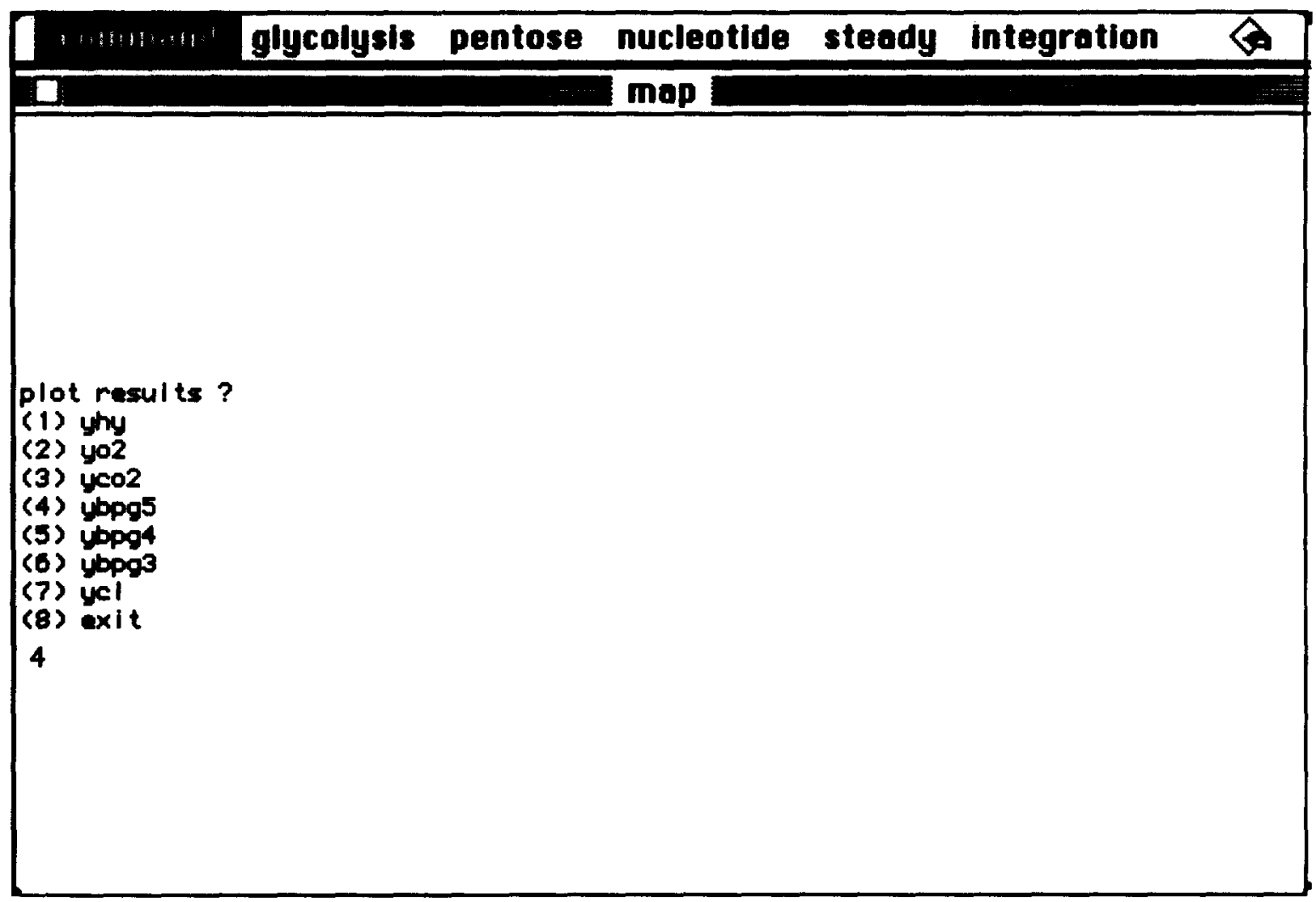

To plot another ligand binding curve, type 'return' and choose a ligand.

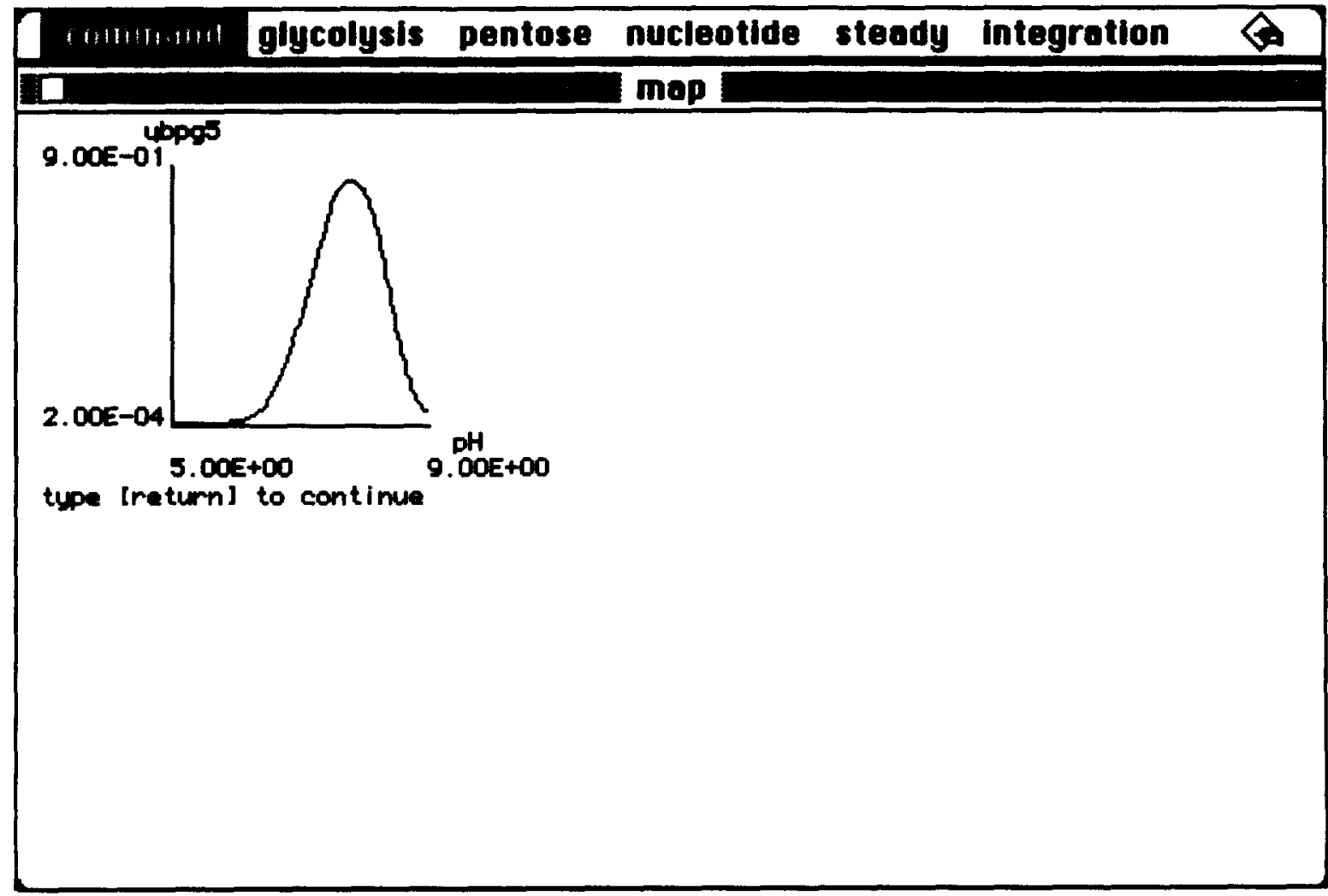




\section{Simulation results}

This section presents simulation results calculated from the model. These calculations also illustrate the utility of the red cell metabolic model.

\subsection{Steady state metabolite concentrations}

One of the primary capabilities of this program is to predict the steady state metabolic concentrations under a given condition. This calculation can be applied to study the red cell metabolism under (1) enzyme deficiency: where any kinetic parameter of the 43 red cell enzymes can be varied in the model, (2) altered extracellular conditions: such as $\mathrm{pH}$, osmolarity, glucose, and lactate, and (3) abnormal intracellular hemoglobin, magnesium, total GSH, NADH, and NADPH concentrations. The physiological steady state metabolic concentrations are calculated and compared with the literature data (Table 11). The calculated numbers agree well with the experimental data. It is worthwhile to note that the intracellular concentration data for human red cell may vary from one subject to another due to

TABLE 11

Steady state concentration of red cell intermediates

\begin{tabular}{|c|c|c|c|}
\hline Metabolite & Model (mM) & Literature (mM) & Reference \\
\hline$\overline{\mathrm{G} 6 \mathrm{P}}$ & 0.040 & $0.038 \pm 0.012$ & {$[20,21]$} \\
\hline F6P & 0.019 & $0.016 \pm 0.003$ & {$[20,21]$} \\
\hline FDP & 0.011 & $0.0076 \pm 0.004$ & {$[20,21]$} \\
\hline DHAP & 0.13 & $0.14 \pm 0.08$ & {$[20,21,22]$} \\
\hline GA3P & 0.0059 & $0.0067 \pm 0.001$ & {$[20,21]$} \\
\hline $13 \mathrm{DPG}$ & 0.00019 & 0.0004 & {$[20,21]$} \\
\hline 3PG & 0.095 & 0.045 & {$[20,21]$} \\
\hline $2 \mathrm{PG}$ & 0.014 & $0.014 \pm 0.005$ & {$[20,21]$} \\
\hline PEP & 0.024 & $0.017 \pm 0.002$ & {$[20,21]$} \\
\hline PYR & 0.059 & $0.077 \pm 0.05$ & {$[20,21,23,22]$} \\
\hline LAC & 1.36 & $1.10 \pm 0.50$ & {$[20,21]$} \\
\hline $2,3 \mathrm{DPG}$ & 4.02 & $4.5 \pm 0.5$ & {$[24,21,22]$} \\
\hline NADH & 0.0295 & $\dagger$ & {$[23,25,26]$} \\
\hline A & 0.000057 & $0.0012 \pm 0.0003$ & {$[25]$} \\
\hline AMP & 0.148 & $0.080 \pm 0.009$ & {$[20,21]$} \\
\hline ADP & 0.39 & $0.27 \pm 0.12$ & {$[20,21]$} \\
\hline ATP & 1.72 & $1.54 \pm 0.25$ & {$[20,21]$} \\
\hline GL6P & 0.000011 & $\dagger$ & $\dagger$ \\
\hline GO6P & 0.186 & + & $\dagger$ \\
\hline NADPH & 0.0648 & 0.0658 & [26] \\
\hline GSH & 3.32 & $3.21 \pm 1.5$ & [20] \\
\hline RU5P & 0.0129 & $\dagger$ & $\dagger$ \\
\hline R5P & 0.033 & $\dagger$ & $\dagger$ \\
\hline $\mathrm{X} 5 \mathrm{P}$ & 0.039 & $\dagger$ & $\dagger$ \\
\hline S7P & 0.23 & $\dagger$ & $\dagger$ \\
\hline E4P & 0.00047 & $\dagger$ & $\dagger$ \\
\hline PRPP & 0.012 & $0.005 \pm 0.001$ & {$[27,28]$} \\
\hline IMP & 0.018 & 0.010 & {$[27,28]$} \\
\hline INO & 0.000014 & 0.001 & {$[27,28]$} \\
\hline $\mathrm{HX}$ & 0.000057 & 0.002 & {$[27,28]$} \\
\hline R1P & 0.003 & 0.06 & {$[27,28]$} \\
\hline K & 146.0 & 135.0 & {$[29,30]$} \\
\hline $\mathrm{Na}$ & 12.7 & \pm 6.0 & {$[29,30]$} \\
\hline
\end{tabular}

$\dagger$ Exact experimental value is difficult to determine and is not readily available. 
various genetic or pathological reasons, and the data in Table 11 are for a typical human [18].

\subsection{Hemoglobin binding affinity with ligands}

The major function of red blood cell is to transport oxygen from the lungs to tissues, and deliver carbon dioxide in the reverse direction. Therefore, it is important to be able to predict the hemoglobin binding affinity with its ligands under various conditions. The physiological ligands of hemoglobin molecule includes $\mathrm{O}_{2}, \mathrm{CO}_{2}$, $\mathrm{Cl}^{-}, 23 \mathrm{DPG}$, and $\mathrm{H}^{+}$. The interactions between all five ligands with the hemoglobin molecule are accounted for in the metabolic model. The hemoglobin oxygen binding affinity $\left(Y_{\mathrm{O}_{2}}\right)$ under different 23DPG concentrations calculated from the red cell model is shown in Fig. 4. The calculations compare well with the experimental data as discussed in [17]. The results indicate that the hemoglobin molecule becomes more rigid and has less affinity with $\mathrm{O}_{2}$ when 23DPG concentration increases.

\subsection{Metabolic response to extracellular perturbation}

The extracellular conditions of red cell may not be constant under experimental or physiological conditions. The red cell metabolic model is capable of predicting the metabolic response of red cell to a perturbation of extracellular glucose, $\mathrm{pH}$, osmolarity, lactate, or pyruvate. For example: The normal blood glucose concentration is $5 \mathrm{mM}$

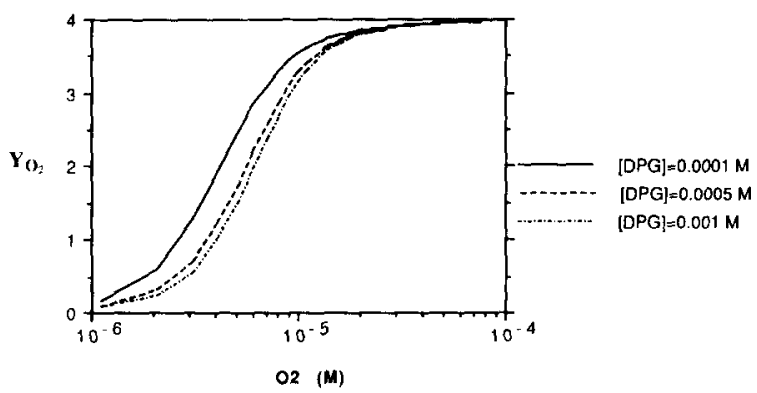

Fig. 4. The hemoglobin binding affinity with oxygen under different 23DPG concentrations.

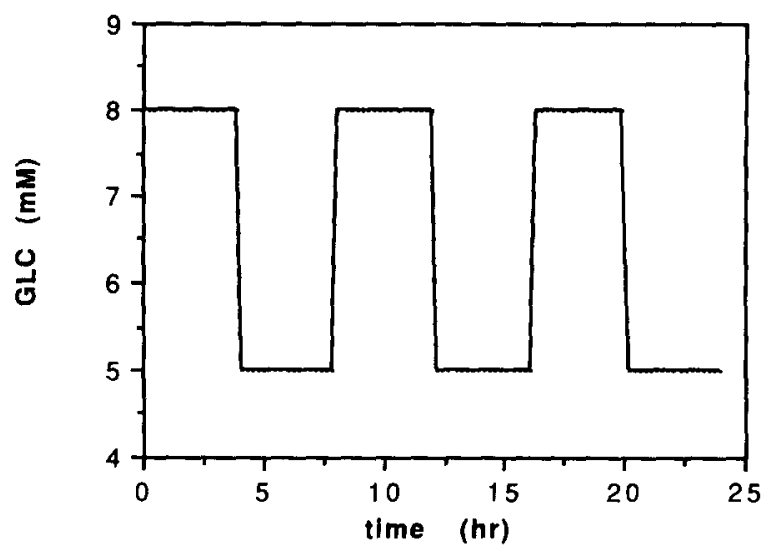

Fig. 5. Suppose a subject eats a meal every $8 \mathrm{~h}$, and his /her blood glucose level remains at $8 \mathrm{mM}$ for $4 \mathrm{~h}$ after a meal and then drops to $5 \mathrm{mM}$ until the next meal. As a result, the blood glucose concentration follows a periodic perturbation.

[20] and rises to $8 \mathrm{mM}$ after a meal. Suppose a subject eats a meal every $8 \mathrm{~h}$, and his/her blood glucose level remains at $8 \mathrm{mM}$ for $4 \mathrm{~h}$ after a meal and then drops to $5 \mathrm{mM}$ until the next meal. As a result, the blood glucose concentration follows a periodic perturbation shown in Fig. 5. The response of red cell intracellular G6P and ATP to the glucose perturbation are calculated from the model and shown in Fig. 6. The results indicate that G6P responds with a significant variation since it is a direct metabolite produced from glucose by enzyme hexokinase. However, the red cell is able to maintain a stable energy (ATP) level regardless of the glucose perturbation.

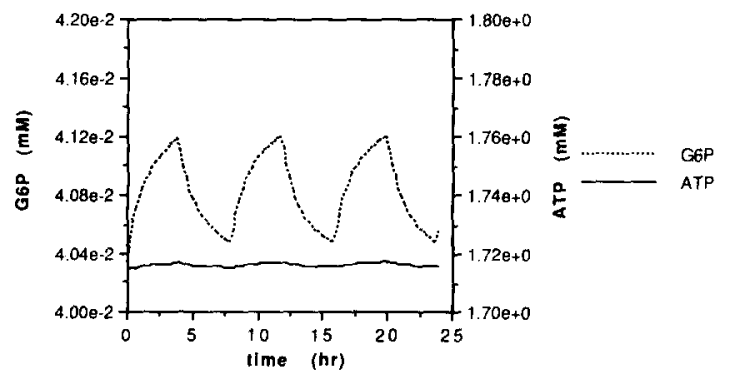

Fig. 6. The response of G6P and ATP to a periodic perturbation of extracellular glucose level. 


\section{Hardware and software specification}

This software package is written for a Macintosh computer with 68020 processor and 68881 coprocessor (such as Mac II and Mac IIci). The memory requirement for this program is $1 \mathrm{MB}$. Data files can be edited by a text file editor such as Edit ${ }^{\mathrm{TM}}$.

\section{Acknowledgement}

This work has been supported by National Institute of Health (grant no. DK 39256).

\section{References}

[1] T.A. Rapoport, R. Heinrich, G. Jacobasch and S. Rapoport, Eur. J. Biochem. 42 (1974) 107-120.

[2] T.A. Rapoport and R. Heinrich, Mathematical analysis of multienzyme systems; i. modeling of glycolysis of human erythrocytes, Biosystems 7 (1975) 120-129.

[3] T.A. Rapoport, R. Heinrich and S.M. Rapoport, The regulatory principles of glycolysis in erythrocytes in vivo and in vitro. Biochem. J. 154 (1976) 449-469.

[4] R. Heinrich, S.M. Rapoport and T.A. Rapoport, Metabolic regulations and mathematical models, Prog. Biophys. Mol. Biol. 32 (1977) 1-82.

[5] F.I. Ataullakhanov, V.M. Vitvitsky, A.M. Zhabotinsky, A.V. Pichugin and O.V. Platonova. The regulation of glycolysis in human erythrocytes, Eur. J. Biochem. 115 (1981) 359-365.

[6] M. Schauer, R. Heinrich and S.M. Rapoport, Mathematische modellierung der glykolyse und des adeninnukleotidstoffwechsels menschlicher erythrozyten. 1. reactionskinetische anatze, analyse des in vivo-zustandes and bestimmung der anfangshedingungen fur die in vitro-experimente, Acta Biol. Med. Germ. 40 (1981) 1659-1682.

[7] M. Brumen and R. Heinrich, A metabolic osmotic model of human erythrocytes, Biosystems 17 (1984) 155-169.

[8] H.G. Holzhutter, G. Jacobasch and A. Bisdorff, Mathematical modeling of metabolic pathways affected by an enzyme deficiency, Eur. J. Biochem. 149 (1985) 101-111.

[9] A. Werner and R. Heinrich, A kinetic model for the interaction of energy metabolism and osmotic states of human erythrocytes, analysis of the stationary in vivo state and of time dependent variations under blood preservation conditions, Biomed. Biochim. Acta 44 (1985) 185-212.

[10] A. Joshi and B.O. Palsson, Metabolic dynamics in the human red cell, part I-a comprehensive model, part II -interactions with the environment, J. Theor. Biol. 141 (1989) 515-545.

[11] A. Joshi and B.O. Palsson, Metabolic dynamics in the human red cell, part $\mathrm{III}$-metabolic reaction rates, part IV-data prediction and some model computations, J. Theor, Biol. 142 (1990) 41-85.
[12] I-Der Lee and B.O. Palsson, A comprehensive model of human erythrocyte metabolism: Extension to include $\mathrm{pH}$ effects. Biomed. Biochim. Acta, 8/9 (1990) 771-789.

[13] J.C. Freedman and J.F. Hoffman, Ionic and osmotic equilibria of human red blood cells treated with nystatin, J. Gen. Physiol. 74 (1979) 157-185.

[14] H. Passow, lon and water permeability of the red blood cell, In: The Red Blood Cell, eds. C. Bishop and D.M. Surgenor (1964).

[15] J.R. Sachs, P.A. Knauf, and P.B. Dunham, Transport through red cell membranes. The Red Blood Cell, ed. D.M. Surgenor, PP. 613-703 (Academic Press, New York San Francisco and London, 1975).

[16] J.W.R. Lawson and R.L. Veech, Effect of $\mathrm{pH}$ and free $\mathrm{Mg}^{++}$on the $\mathrm{K}_{\mathrm{eq}}$ of the creatine kinase and other phosphate hydrolysis and phosphate transfer fluxes, $J$. Biol. Chem. 254 (1979) 6528-6537.

[17] T. Yoshida and M. Dembo, A thermodynamic model of hemoglobin suitable for physiogical applications (Modeling Methodology Forum, American Physiological Society, pp. C563-C577, 1990).

[18] D.O. Cooney, Biomedical Engineering Principles (Marcel Dekker, Inc., New York and Basel, 1976).

[19] L.M. Mcintyre, D.R. Thorburn, W.A. Bubb and P.W. Kuchel, Comparison of computer simulations of f-type and 1-type non-oxidative hexose monophosphate shunts with ${ }^{31} \mathrm{P}$-nmr experimental data from human erythrocytes, Eur. J. Biochem. 180 (1989) 399-420.

[20] E. Beutler, Red Cell Metabolism (Grune \& Stratton, New York, second edition, 1975).

[21] G.S. Jacobasch, S. Minakami and S.M. Rapoport, Cellular and Molecular Biology of Erythrocytes, pp. 55-92 (University of Tokyo Press, Tokyo, 1974).

[22] I. Rapoport, S.M. Rapoport, D. Maretzki and R. Elsner. The breakdown of adenine nucleotides in glucose depleted human red cells, Acta Biol. Med. Germ. 38 (1979) 1419-1429.

[23] W.E. Marshall and U.A. Omachi, Biochim. Biophys. Acta, 354 (1974) $1-10$

[24] G. Gerber, H. Berger, G.R. Janig, K. Ruckpaul and S.M. Rapoport, Vii. internationale symposium uber struktur und funktion der erythrozyten, S.M. Rapoport and F. Jung, eds, pp. 272-282 (Akademie-Verlag, Berlin, 1975).

[25] G.C. Mills, F.C. Schmaltieg, K.B. Trimmer, A.S. Goldman and R.M. Goldblum, Purine metabolism in deaminase deficiency, Proc. Natl. Acad. Sci. USA 73 (1976) 2867-2871.

[26] A. Omachi, C.B. Sott and H. Hegarty, Biochim. Biophys. Acta 184 (1969) 139-147.

[27] I.H. Fox and W.N. Kelley, Phosphoribosylpyrophosphate in man: biochemical and clinical significance, Ann. Inter. Med. 75 (1971) 424-433.

[28] J.F. Henderson and A.R.P. Paterson, Nucleotide Metabolism: An Introduction (Academic Press, New York and London, 1973).

[29] J. Funder and J.O. Weith, Acta Physiol. Scand. 68 (1966) 234-235.

[30] S. Hellerstein, W. Spees and L.O. Surapathana, J. Lab. Clin. Med., 76 (1970) 10-24. 